\title{
El kirchnerismo y sus estrategias políticas en Argentina: Desde la transversalidad hasta Unidad Ciudadana
}

\author{
The Kirchnerism and its political strategies in Argentina: \\ From "transversality" to "Citizen Unity"
}

\author{
Martín Retamozo* Lucía Trujillo**
}

Resumen: Este artículo analiza las diferentes estrategias políticas del kirchnerismo desde su asunción en 2003 hasta las elecciones legislativas de 2017. El estudio muestra cómo las diferentes estrategias "transversalidad" "Concertación Plural" "Partido Justicialista" "Unidos y Organizados" y "Unidad Ciudadana" obedecen a específicos modos de entender aspectos centrales como la representación política, el sistema político y la relación entre los actores políticos en diferentes momentos del ciclo político.

Palabras clave: Argentina, kirchnerismo, estrategias políticas, sistema político

\begin{abstract}
This article analyzes the diverse political strategies of "Kirchnerismo" from his presidential inauguration in 2003 until the legislative elections in 2017. The study shows how the different strategies: "transversality", "Plural Concertation", "Justicialist Party", "United and Organized", and "Citizen Unity" obey different ways of understanding the political representation, the political system and the relationship between political actors at different moments of the political cycle.
\end{abstract}

Keywords: Argentina, Kirchnerismo, political strategies, political system

Recibido: 6 abril 2018 Aceptado: 30 mayo 2018

* IdIHCS- UNLP/CONICET. Investigador del CONICET. Doctor en Ciencias Sociales (FLACSO-México). Profesor de Filosofía y Magister en Ciencias Sociales. (Universidad Nacional de La Plata- UNLP, Argentina). Profesor del Doctorado en Ciencias Sociales y en la Licenciatura en Sociología (UNLP), $₫$ martin.retamozo@gmail.com

** IdIHCS- UNLP/CONICET. Doctora en Ciencias Sociales (UNLP- Argentina) Magister en Gobierno y

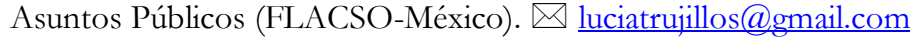




\section{Introducción. De tácticas y estrategias}

La victoria, es decir, el éxito táctico, en principio es tan sólo un medio para la estrategia y en última instancia, los hechos que han de conducir a la paz son los que constituyen su objetivo final. El empleo de ese medio para alcanzar el objetivo va acompañado también de circunstancias que ejercen más o menos influencia sobre él.

(Karl Von Clausewitz)

Luego de la dislocación política y económica de finales de 2001 en Argentina se abrió un nuevo tiempo político. La salida de la Convertibilidad ${ }^{1}$, que estructuraba la forma del neoliberalismo argentino, requirió la recomposición de condiciones de gobernabilidad para que el sistema político pudiera procesar las demandas ciudadanas en el nuevo régimen económico y político. Con el "QQue se vayan todos!", aun retumbando los espacios públicos y la presencia de colectivos activamente movilizados, la convocatoria a elecciones presidenciales por parte de Eduardo Duhalde - precipitadas luego del asesinato de Maximiliano Kosteki y Darío Santillánparecía un experimento crucial en relación a la posibilidad de restablecer la legitimidad de las formas de representación (aunque la legitimidad de los representantes quedara todavía en cuestión). La masividad de los votos positivos y la baja abstención, en contraste con las elecciones de 2001, fueron signos de una nueva fase en la historia política ${ }^{3}$. Producto de esas elecciones asumió la primera magistratura Néstor Kirchner, luego de que Carlos Menem, quién había obtenido el 24,45\% de los votos contra el 22,25\% de Kirchner, desistiera de participar de la segunda vuelta.

La asunción de un "presidente inesperado" según la definición de José Natanson", sin capital gran político propio, que jugó en los intersticios de la dislocación abrió un campo en el que se configuraron nuevas coordenadas para la acción política. Entre la actualización particular de la tradición peronista y el horizonte de la renovación, el devenir kirchnerismo ${ }^{5}$ construyó una serie de estrategias que produjo una reconfiguración el campo político en el que, a su vez, se autoconstituyó como una fuerza política central hasta la actualidad.

1 El régimen de Convertibilidad estableció en 1991 la paridad por ley entre el peso argentino y el dólar estadounidense. Esta medida constituyó una particularidad argentina en el marco de las reformas típicamente neoliberales orientadas a la privatización de empresas estatales, desregulación de la economía y apertura a las importaciones. Hacia fines del año 2001 la situación argentina estaba marcada por altos índices de desocupación, pobreza y una recesión económica arrastrada desde el año 1998.

2 La consigna ¡"Que se vayan todos!” aglutinó a heterogéneos sectores que protestaban por la situación socioeconómica, las restricciones al retiro de los depósitos de los bancos y las medidas represivas del último tramo del gobierno de la Alianza (1999-2001)

${ }^{3}$ Las elecciones legislativas de octubre de 2001, registró una conducta del "voto bronca" plasmado tanto en el nivel de abstención (24.53\%) y de votos anulados o en blanco (23.97\%), índices muy altos para la historia argentina. En 2003 la participación fue del 78\%, los votos en blanco 0,99 \% mientras que los votos anulados el $1,73 \%$

${ }^{4}$ Natanson, José. El presidente inesperado. Editorial Homo Sapiens, Buenos Aires. 2004.

5 Hablamos de "devenir kirchnerismo" en tanto el kirchnerismo como tal no se constituyó con la asunción del presidente el 25 de mayo de 2003 sino que lo consideramos un proceso secuencial cuyo período formativo se extiende entre 2003 y 2010. 
El término "estrategia" que incluimos en el título puede llevar a una confusión en tanto en el campo de las ciencias sociales este concepto ha sido utilizado predominantemente por los enfoques de la elección racional. En enfoque "estratégico" de los movimientos sociales, asociado al paradigma norteamericano primero como Teoría de la Movilización de Recursos y luego como Proceso político a partir de los trabajos de Charles Tilly, Doug Mc Adam y Sidney Tarrow, recuperó el término ligado a problemas de coordinación. Esto implicó definir dos dimensiones relacionadas a la movilización social. La primera enfocada en pensar los problemas de coordinación de las acciones de los individuos para obtener la acción colectiva (bajo una lógica de elección racional). La segunda para comprender el comportamiento de las organizaciones del movimiento social en contextos políticos o estructura de oportunidades. La estrategia, en ambas perspectivas, supone considerar la acción de los otros como factor clave para definir la elección entre las opciones restringidas por el contexto (o las reglas del juego) y los recursos disponibles pero la naturaleza de los agentes que construyen estrategias difiere significativamente.

En este trabajo concebimos la estrategia como una resultante de interacción de actores que coordinan en aras de fines que pueden ser múltiples y simultáneos. Sin embargo, para analizar la política, este enfoque se encuentra con dos situaciones que lo complejizan y enriquecen. La primera radica en que la estrategia no se agota en la decisión de un actor racional maximizador sino que implica coordinar partidos, movimientos, fracciones y colectivos con capacidad de agencia, con lo que la estrategia es una resultante de interacciones. El segundo es que no siempre existe un solo escenario para la acción, en tanto conviven objetivos múltiples como el desempeño electoral, representación política, ordenamiento del sistema político, etc. Esto genera importantes desafíos para la investigación.

Ahora bien, aunque la estrategia es la resultante de una interacción hay agentes privilegiados en tanto tienen capacidades (y recursos) para definir tácticas o modificar escenarios, decidir aportar recursos o establecer "salida, vOz y lealtad" como dice Hirschman". A diferencia de la guerra donde hay línea de mando férrea, en la política (en particular en la "movimientista" como en el caso del peronismo), diferentes agentes toman decisiones, coordinan y disputan con disímiles capacidades y recursos. Pero, además, los escenarios o las arenas políticas varían y también las gramáticas que las componen y las regulan (incluso por efecto de las acciones de los agentes). Las elecciones, por ejemplo, tienen ciertas reglas que, a su vez, pueden ser disputadas (por medios de reformas institucionales) y tensionadas en sus regulaciones. Las decisiones gubernamentales poseen otras regularidades marcadas por restricciones legales, burocráticas y de capacidades estales. Por su parte, las tácticas discursivas requieren de otras dimensiones de análisis ligadas a los enunciadores, las polifonías, las audiencias, la interpelación y la recepción.

\footnotetext{
${ }^{6} \mathrm{El}$ concepto "estrategia" tiene un origen en la teoría militar, Aristóteles, en la Ética a Nicómaco la asocia a la "ciencia de la oportunidad", y lo inscribe en una lógica de medios y fines que perdurará en enfoques sociológicos y politológicos. SunTzu, el otro gran estratega, identifica cinco factores claves para considerar y que influyen en el éxito de la acción "El primero de estos factores es la doctrina; el segundo, el tiempo; el tercero, el terreno; el cuarto, el mando; y el quinto, la disciplina", algo que nos dará una pauta de elementos para tener en cuenta a la hora de traducir el problema en el campo políticoSun Tzu "El arte de la guerra" en AAVV Genios del arte de la estrategia militar (I). Ediciones LAVP. New York. , 2015, p.13)

${ }^{7}$ Hirschman, Albert O. Salida, vozy lealtad. Fondo de Cultura Económica. México, 1977
} 
Aquí consideramos que el acto político es, por definición, performativo (o con pretensión de performatividad) y bifronte. Por un lado, busca modificar (o preservar) aspectos de las relaciones sociales constitutivas de la comunidad política y por otro actúa recursivamente sobre las propias reglas del juego, la distribución de los recursos o lo contextos. En esta perspectiva, este trabajo expone y analiza las sucesivas estrategias políticas que desde el espacio kirchneristas se instrumentaron en diferentes momentos y con objetivos distintos (o jerarquizados de diferente manera) a partir de la asunción de Néstor Kirchner, cuando el nuevo presidente enfrentó un desafío que puede sintetizarse en "Cómo construir poder, con un poquito de poder y en un lugar de poder". Esto implica una situación de partidas múltiples y, en cierto modo, anidadas, para evocar el concepto de Tsebelis ${ }^{8}$. En efecto, no sólo se trataba de construir gobernabilidad -algo que medianamente había aportado el gobierno de Eduardo Duhalde- sino gobernanza, es decir, transformar las condiciones donde se ejerce la goberanbildiad. Simultáneamente se presentaban desafíos en lo que concierne a configurar la fuerza propia y en la definición de las tácticas electorales frente a los comicios que se sucederían en $2003^{9}$ y que marcarían los destinos del nuevo gobierno. Estos cuatro desafíos: Gobernabilidad, fuerza propia, régimen político y estrategia electoral marcan ritmos y ayudan a explicar el despliegue del proceso desde 2003 y las diferentes estrategias que son analizadas en la sección siguiente.

\section{La construcción post-electoral: De la opinión pública a la transversalidad}

La restitución de la gobernabilidad en los albores del kirchnerismo se basó en tres pilares fundamentales. El primero, la consolidación de un patrón de crecimiento postconvertibilidad que, luego de la devaluación y la transferencia hacia sectores concentrados, comenzó a mostrar signos de recuperación ${ }^{10}$. El segundo la recomposición de la legitimidad institucional en torno a los mecanismos de la democracia representativa fuertemente afectados en la crisis del 2001 y $2002^{11}$. El tercero el consenso en torno la figura de un presidente que llegaba luego de la defección de quién obtuviera la mayor cantidad de votos en las elecciones de 2003 y que carecía de bases de apoyo organizativas propias ${ }^{12}$

Dada la primera condición, la recuperación económica, Néstor Kirchner procuró la tarea simultánea de consolidar la restitución el lazo representativo, construir consenso en torno a su figura y recomponer una fuerza de gobierno capaz de garantizar la gobernabilidad. Esto implicó una serie de medidas como el relevamiento de la cúpula militar, la renovación de la cuestionada Corte Suprema de Justicia, la intervención de la obra social de los jubilados (PAMI) y el aumento del salario mínimo por decreto, entre otras acciones ejecutivas

\footnotetext{
8 Tsebelis, George. Nested games: Rational choice in comparative politics. Vol. 18. Univ of California Press, 1990.

${ }^{9} \mathrm{La}$ dimensión electoral en Argentina tiene una característica insoslayable en la territorialización y desnacionalización, por lo tanto, nos enfocamos en el nivel nacional y en el de la provincia de Buenos Aires. Al respecto ver: Calvo, Ernesto. "Argentina, elecciones legislativas 2005: consolidación institucional del kirchnerismo y territorialización del voto." Revista de ciencia política (Santiago) 25.2 (2005): 153-160.

10 Santarcángelo, Juan E., Juan Fal, and Germán Pinazo. "Los motores del crecimiento económico en la Argentina: rupturas y continuidades." Investigación económica 70.275 (2011): 93-114.

11 Cheresky, Isidoro. "Argentina. Cambio de rumbo y recomposición política: Néstor Kirchner cumple un año de gobierno." Nueva Sociedad 193 (2004): 4-16.

12 Muñoz, María Antonia, and Martín Retamozo. "Hegemonía y discurso en la Argentina contemporánea: Efectos políticos de los usos de" pueblo" en la retórica de Néstor Kirchner." Perfiles latinoamericanos 16.31 (2008): 121-149.
} 
acompañadas de un discurso fuertemente rupturista con los años noventa y el neoliberalismo. La recomposición no se agotó en medidas que atendían demandas de "opinión pública" sino también en un estilo de proximidad que se condensaba en el iterado "soy un hombre común con responsabilidades importantes"13. Este incipiente "regreso del líder" para tomar prestado el giro del politólogo mexicano Sergio Zermeño ${ }^{14}$ reactivó un debate en el campo de la teoría política sobre los modos de representación y liderazgos adjudicados clásicamente al populismo $^{15}$. En efecto, el ejercicio del liderazgo de Néstor Kirchner (como luego de Cristian Fernández de Kirchner) adquirió rasgos que sucintaron debates teóricos específicos en aras de forjar categorías para comprender el fenómeno dada su centralidad en el proceso político. ${ }^{16}$

En lo que refiere a la configuración de un esquema de representación política, ya en el discurso de asunción el 25 de mayo de 2003 Kirchner exponía: "La Argentina contemporánea se deberá reconocer y refundar en la integración de equipos y grupos orgánicos, con capacidad para la convocatoria transversal, el respeto por la diversidad y el cumplimiento de objetivos comunes." (...) "Se necesitará mucho trabajo y esfuerzo plural, diverso y transversal a los alineamientos partidarios."

La estrategia conocida como "transversalidad" consistió en la apertura a la incorporación de cuadros, sectores de partidos y movimientos sociales en una suerte de inclusión subordinada que operaba sobre los escombros del sistema de representación partidario. Para Juan Carlos Torre era una "operación política puesta en marcha por el presidente Kirchner con vistas a incorporar a su empresa política a sectores de la izquierda peronista y no peronista marginales a las estructuras del partido Justicialista" 18 . Esta convocatoria buscaba atraer a figuras tanto referentes de partidos tradicionales como novedosos emergentes de los años de crisis, así "la primera experiencia "transversal" se dio a partir de marzo de 2004, en la que los interlocutores privilegiados fueron los intendentes Luis Juez, quien se presentó y fue valorado como el contrapunto del estilo político del gobernador De la Sota en Córdoba; Hermes Binner, como uno de los pocos exponentes exitosos del Partido Socialista; y Aníbal Ibarra en la Ciudad Autónoma de Buenos Aires que, en

13 Para un análisis de este tópico: Annunziata, Rocío. "La figura del" hombre común" en el marco de la legitimidad de proximidad: ¿un nuevo sujeto político? "Astrolabio Nueva Época: Revista digital del Centro de Investigaciones y Estudios sobre Cultura y Sociedad 10 (2013): 127-155.

14 Zermeño, Sergio. "El regreso del líder: crisis, neoliberalismo y desorden." Revista Mexicana de Sociología (1989): 115-150.

${ }^{15}$ En la teoría política latinoamericana, uno de las controversias destacadas gira en torno al liderazgo y los modos de representación en el populismo. Al respecto: Peruzzotti, Enrique. "Populismo y representación democrática." En AAVV El retorno del pueblo. Populismo y nuevas democracias en América Latina (2008): 55-73.

16 Un conjunto de trabajos gira en torno al tema, entre ellos: Casullo, María Esperanza. "¿En el nombre del pueblo? Por qué estudiar al populismo hoy." Postdata 19.2 (2014); Ostiguy, Pierre. "Exceso, representación y fronteras cruzables:" institucionalidad sucia", o la aporía del populismo en el poder." Postdata 19.2 (2014); Barros, Sebastián. "Populismo, pueblo y liderazgo en América Latina." Colombia Internacional 82 (2014): 297-302.; Freidenberg, Flavia). ¿Qué es el populismo? Enfoques de estudio y una nueva propuesta de definición como un estilo de liderazgo. el populismo en Latinoamérica: teoría, bistoria y valores. Francia: Presses Universitairess de Bordeaux. 2012

17 Para un análisis de la dimensión paradestinataria ligada a la transversalidad en el discurso kirchnerista ver Montero, Ana Soledad. Puesta en escena, destinación y contradestinación en el discurso kirchnerista (Argentina, 2003-2007). Discurso \& Sociedad, 3(2), 2009. 316-347

18 Torre, Juan Carlos. "La operación política de la transversalidad. El presidente Kirchner y el Partido Justicialista." Conferencia UTDT, noviembre de 2004 p.2. 
consonancia con los dirigentes provenientes del FREPASO de raigambre peronista, mostró una clara afinidad con el gobierno de Kirchner" 19

Es decir, por un lado se evidenciaba un intento de aglutinar a sectores y cuadros pertenecientes a organizaciones políticas externas al Partido Justicialista con una orientación progresista o nacional-popular (e incluso peronistas ${ }^{20}$. Por otro se constituía un llamado a sectores que habían permanecido marginados dentro del justicialismo y una alianza con distintas elites políticas que habían llegado a los poderes locales (municipales o provinciales). Pero un análisis de la transversalidad estaría incompleto sin la inclusión de los movimientos sociales que forzaron la centralidad de la estrategia. En efecto, las respuestas a demandas de la opinión pública fueron acompañada de diversos modos de gestión de demandas tramitadas por colectivos movilizados, fundamentalmente de desocupados pero también de derechos humanos $^{21}$. Esta relación del ejecutivo con los movimientos sociales, que fue leída por algunos autores como "cooptación" 22 , implicó la posibilidad de encauzar institucionalmente ciertas demandas, fragmentar la protesta y configurar un campo identitario en el que progresivamente se fueron inscribiendo y reconociendo ciertos líderes y organizaciones ${ }^{23}$. El proceso no fue lineal, basta recordar dos declaraciones recuperadas por Laura Vales, periodista de Página/12, el 3 de agosto de 2003: "No somos kirchneristas, no somos parte del Gobierno ni del kirchnerismo" decía Emilio Pérsico referente del por entonces Movimiento de Trabajadores Desocupados Evita (MTD-Evita) mientras que Luis D'elia afirmaba "Mientras el Presidente siga así, somos kirchneristas". Por su parte "Aclare que no somos kirchneristas", puntualiza, "ni antikirchneristas tampoco" pedía Gabriel Fernández del MTD Resistir y Vencer ${ }^{24}$. Aunque todos habían confluido en el homenaje a Eva Perón del 26 de julio y luego asumirían cargos durante el kirchnerismo y una indiscutible pertenencia a ese espacio político. Esta es, sin dudas, una de las dimensiones de la transversalidad que significó el vínculo-mediado por cuadros de la secretaría de la presidencia y por recursos- con referentes de espacios activos en el campo de la protesta social y la organización territorial.

Lo anterior evidencia una triple inscripción de la transversalidad: como táctica electoral, cómo construcción de poder propio y cómo intento de incidir en la conformación del escenario. En la dimensión electoral, el capital político inicial obtenido por Néstor Kirchner le permitió instrumentar una serie de heterogéneas tácticas como el apoyo al ex Frepasista Aníbal Ibarra como jefe de gobierno (que derrotó a Mauricio Macri), por un lado, y el aval a la candidatura de Felipe Solá a la gobernación de la provincia de Buenos Aires. En efecto "En

\footnotetext{
${ }^{19}$ Lucca, Juan Bautista. "Conflictos y realineamientos de los actores sociales y políticos durante el gobierno de Néstor Kirchner." Sudamérica: Revista de Ciencias Sociales 3 (2014), p. 35

20 Al kirchnerismo se incorporaron cuadros provenientes del Frente Grande, del casi extinto Frepaso o del Partido Intransigente. Por otro lado, sectores que no habían abandonado el Partido Justicialista y que buscaban reinscribirse dada su posición relativamente marginal y finalmente cuadros como no provenían de experiencias nacional-populares como Gustavo Béliz, Martín Redrado, Luis Juez o Graciela Ocaña, ver:

21 Retamozo, Martín. "Movimientos sociales, política y hegemonía en Argentina." Polis. Revista Latinoamericana 28 (2011).

${ }^{22}$ La hipótesis de la cooptación fue ampliamente criticada por restar capacidad de agencia a las organizaciones e invisibilizar el problema sociológico de explicar el modo de articulación y comprender la racionalidad del proceso mismo.

23 Esta operación de articulación de demandas insatisfechas es una característica del populismo como lógica política según lo teorizó Ernesto Laclau en La razón Populista, FCE, Buenos Aires.

${ }^{24}$ Laura Vales "los muchachos piqueteros” Diario Página/12, de agosto de 2003
} 
aquellas provincias en que ha podido ha favorecido a candidatos leales a su proyecto en detrimento de la unidad partidaria, favoreciendo una estrategia de transversalidad, es decir de agrupamiento ideológico transpartidario, en vistas a incrementar su poder, que tiene cierto grado de eficacia porque está inspirada desde el aparato estatal”"25. El resultado de la táctica electoral redundó en la consolidación de poder institucional y capital político. Todo el raid electoral de 2003 arrojó un saldo positivo para las fuerzas aliadas a Néstor Kirchner y el PJ acabó el año con mayoría en la cámara de diputados y en la cámara de senadores ${ }^{26}$. Esto también fue incrementando la fuerza propia ya que paulativamente se fueron sumando colectivos que de distinto modo se acercaron al núcleo kirchnerista (Schuttembarg, 2014) ${ }^{27}$

Los primeros meses del 2004 marcaron una nueva fase tanto en lo que respecta a la configuración de una fuerza propia como por la estrategia electoral de cara al 2005. Con motivo de la celebración del triunfo electoral de Hector J. Cámpora en 1973, el 11 de marzo se convocó al "Primer Encuentro de la Militancia" en Parque Norte que la prensa analizaba como la ocasión en que "el kirchnerismo dará el primer paso para la conformación de una única estructura electoral que compita en todas las provincias del país" 28 . Allí se dieron cita funcionarios del Poder Ejecutivo como Alberto Fernández, José Pampuro, Alicia Kirchner, Carlos Tomada, Gustavo Beliz, Daniel Filmus; Martín Redrado; Graciela Ocaña; Eduardo Luis Duhalde; Enrique Albistur; Entre los gobernadores, Eduardo Fellner y Carlos Rovira, Jorge Busti y Felipe Solá. También el intendente de Córdoba, Luis Juez; y los sindicalistas Hugo Moyano, Gerónimo Venegas (62 Organizaciones), Eduardo Depetri (CTA) y Víctor Santa María; y Luis D’Elia y Jorge Ceballos. Además de legisladores como, Alicia Castro, Vilma Ibarra, Juliana Marino, Francisco Gutiérrez y Miguel Bonasso.

La transversalidad como estrategia, sin embargo, no se agotaba en la pretensión de amalgamar una fuerza propia sino, que "la transversalidad portaba una pretensión de instituir eventualmente un nuevo clivaje que reorganizara políticamente a la sociedad argentina" 29 . En efecto, como afirma Cheresky, "El proyecto reformista del Presidente Kirchner parece necesitar y a la vez fomentar en cierta medida la descomposición de los partidos tradicionales y en particular del peronismo, aunque el futuro de esta estrategia sea dudoso porque deberá contar con apoyo institucional, y para ello probablemente recurrir a compromisos con parlamentarios y dirigentes de su partido"30. Esta tensión se plasmó en el mencionado Encuentro de la Militancia en Parque Norte donde lo que en un comienzo se convocó como un espacio propiamente kirchnerista por fuera del partido se convirtió, con la llegada de dirigentes peronistas, en un espacio de articulación entre sectores tradicionales del Partido

\footnotetext{
${ }^{25}$ Cheresky, 2003, Op. Cit., Pp. 94-95

${ }^{26} \mathrm{El}$ incremento en la representación legislativa a nivel nacional se produjo debido al tipo de negociación que el kirchnerismo estableció con fuerzas subnacionales. Allí el gobierno nacional tuvo más incidencia en la selección de candidatos a cargos legislativos nacionales y cedió espacios locales

27. Schuttenberg, Mauricio. Las identidades nacional populares: De la resistencia noventista a los años kirchernistas. Eduvim. Villa María. 2014

${ }_{28}^{8}$ Martín Pique “Los kirchneristas en acción” Diario Página/12. 11 de marzo de 2005.

29 Rocca Rivarola, Dolores. Definiciones de pertenencia e identidades oficialistas en la Argentina de Néstor Kirchner y el Brasil de Luiz Inácio Lula da Silva. En Cheresky (Ed.) Ciudadanía y legitimidad democrática en América Latina, CLACSO-Prometeo, Buenos Aires. 2011, p. 2012

30 Cheresky, Isidoro, En nombre del pueblo y de las convicciones: Posibilidades y límites del gobierno sustentado en la opinión pública. POSTData, 9, p. 94
} 
Justicialista y el novedoso espacio kirchnerista. Montero y Vicent ${ }^{31}$ identifican a esos acontecimientos de marzo como el cierre de una etapa de transversalidad y la apertura hacia el "peronismo impuro". Ahora bien, este período puede considerarse como una instancia simultánea entre la conformación de la propia fuerza y el intento de reconfiguración de los espacios de representación política. Para ello se tornó como algo clave matar al padrino de la victoria electoral del 2003, es decir, destronar al duhaldismo como eje articulador de la política del Partido Justicialista.

El PJ se transformó, entonces, en una arena en disputa que se materializó en la convocatoria al Consejo Nacional del Partido Justicialista el 27 de marzo de 2004 en Parque Norte, el mismo escenario del encuentro kirchnerista. Allí, se produjo un fuerte debate entre Cristina Fernández de Kirchner e Hilda "Chiche” González de Duhalde, esta controversia en torno al lugar de la mujer en los procesos políticos era un síntoma de dos posiciones al interior del peronismo. Luego de duros intercambios el encuentro no logró consolidar una normalización del Partido Justicialista dando lugar a un escenario de enfrentamiento entre los sectores encabezados por Eduardo Duhalde y los comandados por Néstor Kirchner.

El cuestionamiento a la deriva Partido Justicialista no era nuevo en el acervo discursivo de Néstor Kirchner. Previo a su asunción como presidente, en un libro de diálogos con Torcuato Di Tella, Kirchner se atribuía la autoría del término pejotismo "¿Sabe a qué llamo pejotismo? Para mí define la deformación a la que llevó Menem al Partido Justicialista: un aparato de poder vaciado de contenido, $\sin$ ideas" ${ }^{\prime 2}$ (. No obstante, ya en ejercicio del ejecutivo, lo que Kirchner disputaba no era el lugar del sello partidario sino la jefatura del peronismo como movimiento político. La estrategia se nutrió de la transversalidad pero en clave de alianza con ciertos sectores del peronismo con representación a nivel nacional y subnacional $^{33}$. El peronismo volvía a funcionar como un sistema político en sí mismo ${ }^{34}$ generando un oficialismo y una oposición que se plasmó en las elecciones de 2005.

En el camino hacia las elecciones lesgislativas de 2005 se configuro un espacio de representación nacional-popular que fue capaz de aglutinar desde dirigentes y organizaciones provenientes del Partido Justicialista, del campo sindical ligado al peronismo ${ }^{35}$, hasta otras expresiones organizativas que fueron interpeladas por el discurso y las acciones de la fuerza gobernante. Entre estas últimas puede contarse el proceso de convergencia de una seria de

31 Montero, Ana Soledad, and Lucía Vincent. "Del" peronismo impuro" al" kirchnerismo puro": la construcción de una nueva identidad política durante la presidencia de Néstor Kirchner en Argentina (20032007)." Postdata 18.1 (2013):

32 Kirchner, Néstor, and Torcuato S. Di Tella. Después del derrumbe: teoría y práctica política en la Argentina que viene. Editorial Galerna, 2003, p. 131

33 En la lista de diputados nacionales por la provincia de Buenos Aires puede notarse la primacía de cuadros del Partido Justicialista y la aparición de la ex Frepasista Diana Conti, y el peronista proveniente del Polo Social y dirigente de la UOM Francisco "Barba" Gutierrez"

34 Torre, Juan Carlos "El peronismo como solución y como problema", en Novaro, Marcos (comp.), Entre el abismo y la ilusión. Peronismo,

democracia y mercado, Buenos Aires, Norma. 1999

${ }^{35}$ En efecto, Néstor Kirchner apoyó la asunción de Hugo Moyano como Secretario General de la CGT en julio de 2005 y la alianza con el sector sindical conducido por el líder camionero duró varios años. En menor medida en esta etapa puede observarse un vínculo con la CTA, en particular con sectores conducidos por Edgardo Depetri. Al respecto ver: Retamozo, Martín, and María Belén Morris. "Sindicalismo y política. La Central de Trabajadores de la Argentina en tiempos kirchneristas." Estudios sociológicos 33.97 (2015): 63-87. 
organizaciones protagonistas de la "resistencia" al neoliberalismo con gran capacidad de movilización y buena disposición de cuadros políticos pero escasa eficacia en la arena electoral. Desde finales de 2003 pero fundamentalmente durante el 2004 las organizaciones de matriz nacional-popular fueron convergiendo en movilizaciones e intentos de articulación organizativa. Varias organizaciones firmaron un documento "La Hora de los Pueblos" (20/6/2004) y para el 26 de julio elaboraron una declaración de apoyo al presidente Néstor Kirchner que fue firmada por la FTV, Barrios de Pie, el MTD Evita, el PCCE y el Movimiento Barrial Octubres. El intento más avanzado fue quizás la "Declaración política del Frente de Organizaciones Populares" (20/9/2004) y luego la "Declaración de la Mesa Coordinadora Para un Proyecto Nacional” (27/9/2004) firmada por Miguel Bonasso (PRD), Luis D’Elía (FTV) Jorge Ceballos (Barrios de Pie) Edgardo Depetri (FTNyP) Emilio Pérsico MTD Evita), Marcelo Koening (MP 20) y Gastón Harispe (Movimiento Octubres) entre otros. El 12 de octubre de 2004, en un acto en el estadio Luna Park las organizaciones transversales presentaron públicamente el nucleamiento (Página/12, 13/10/04). A fines de 2004 estas organizaciones conformaron el Frente Patria Para Todos en cuyo congreso fundacional de diciembre participó Oscar Parilli, secretario general de la presidencia como señal de aval de Néstor Kirchner al armado.

Las elecciones de 2005 cierran una fase en el que el kirchnerismo jugó una estrategia selectivamente fragmentada que incluía una carta de "peronismo kirchnerista" en la provincia de Buenos Aires a la vez que diferentes acuerdos partidarios y extrapartidarios en las distintas provincias. Según Calvo "Para ganar la provincia de Buenos Aires el kirchnerismo apuntó a (i) capturar parte del voto duhaldista mediante alianzas estratégicas con intendentes del conurbano, el cinturón industrial que rodea a la Ciudad de Buenos Aires y que incluye a los distritos más populosos de la Provincia. Por otro lado, (ii) Néstor Kirchner apeló a un discurso de 'transversalidad' política, como fuera definida desde el gobierno la estrategia de sumar votos de la centro-izquierda no peronista." ${ }^{36}$. De acuerdo a la contabilización de Matilde Ollier ${ }^{37} 48$ de los 76 intendentes peronistas apoyaron al kirchnerismo en la contienda electoral. El 27 de abril de 2005 CFK lanzó su campaña por bajo el sello Frente para la Victoria, pero desde un atril en el que se destacaba el escudo del Partido Justicialista (en parte porque el acto era la oficialización de la normalización del PJ de Capital) Para Murillo y Levitsky "Los esfuerzos kirchneristas por formar un movimiento "transversal" al margen de la maquinaria del PJ, compuesto por peronistas progresistas y miembros de la izquierda no peronista, nunca consiguieron adhesión. Aunque Kirchner inicialmente alejó a algunos jefes de partidos, finalmente los necesitó para procurar los votos. Antes de la elección de 2005, hizo las paces con la maquinaria del partido, y abandonó el proyecto transversal" 38 . Sin embargo, si bien es cierto que en la contienda existieron importantes dirigentes justicialistas que optaron por alinearse con el kirchnerismo, el Partido Justicialista oficial estuvo del lado del ex gobernador de la provincia de Buenos Aires.

36 Calvo, Ernesto. "Argentina, elecciones legislativas 2005: consolidación institucional del kirchnerismo y territorialización del voto." Revista de ciencia política (Santiago) 25.2 (2005), p. 156.

37 Ollier, María Matilde. "Liderazgo presidencial y jefatura partidaria: entre la confrontación y el pacto (20032005)". Revista Temas \& Debates 10, (2005) pp. 7-33

38 Levitsky, Steven, and M. Murillo. "Argentina. De Kirchner a Kirchner" Journal of Democracy en español 1: Pp. 8384. 
La victoria de CFK sobre Hilda "Chiche" González de Duhalde y el resultado a nivel nacional cercenó las opciones para que otros líderes del peronismo como José Manuel de la Sota, los hermanos Rodriguez Saa o el ex presidente Carlos Menem pudieran pensar en un PJ que se aparte de la estrategia presidencial. La conformación de las cámaras de diputados y senadores evidenció un incremento de la presencia del peronismo alineado al kirchnerismo y un crecimiento de bloques aliados al presidente Kirchner. Con el PJ neutralizado y las elecciones presidenciales de 2007 en el horizonte Néstor Kirchner declararía a fines de 2006 que "La transversalidad fue una denominación periodística. Es un término que podría funcionar en un sistema de partidos que están funcionando. En la Argentina, todos sabemos que la reconstrucción de los partidos políticos va a llevar un tiempo largo. Entonces, la construcción del espacio se debe hacer en base a ideas superadoras que seguramente provendrán de hombres y mujeres de distintos partidos"39, y así anunciaba el desplazamiento estratégico.

\section{La Concertación Plural: entre el gobierno y la coalición electoral}

La fase de transversalidad como estrategia de acumulación de poder, capacidad de gestión y gobernabilidad, por un lado, y la disputa con los sectores del partido justicialista encabezado por Eduardo Duhalde, por otro, puso en evidencia dos arenas centrales y sus juegos anidados. La constitución de una fuerza propia, incluso con identidad ligada al "genero próximo" (el peronismo) y la "diferencia específica" (el kirchnerismo) que remitía a un espacio simbólico compartido "nacional-popular". Asimismo, los resultados electorales mostraban la necesidad de un marco de alianzas que permitiesen aceitar el juego entre desempeño electoral y gobernabilidad institucional.

Ahora bien, si la transversalidad proponía una lógica de articulación, es decir, un proceso en el que los elementos que ingresan en un campo de prácticas que transforman sus identidades al ser parte de un espacio mayor, la concertación evidenció una lógica de alianza de elementos preconstituidos que no abandonaban su pretensión de autonomía ${ }^{40}$. La dimensión de la transversalidad que ligó el kirchnerismo a los movimientos sociales tuvo efectos en la gobernabilidad, otorgó legitimidad y capacidad de acción y movilización, pero no era del todo mecánico su traslado a la arena electoral ${ }^{41}$. De allí que la expansión del marco de alianza con elites partidarias subnacionales constituidas resultara indispensable en la construcción de poder electoral. Esto no implica que una estrategia se reemplaza sobre otra, como dijimos, son arenas diferentes, pero en distintos momentos y coyunturas políticas adquieren dinámicas específicas a la vez que se vinculan.

"Estamos construyendo un espacio político. Algunos hablan de concertación, otros de construcción amplia, otros de vocación frentista. En la etapa que viene en el 2007, más allá de

\footnotetext{
${ }^{39}$ Néstor Kirchner "Lo que diga sobre la reelección no me lo van a creer" entrevista al diario Página/12, 21 de mayo de 2006.

40 Laclau, Ernesto, and Chantal Mouffe. Hegemony and socialist strategy: Towards a radical democratic politics. Verso, London, 1985.

${ }^{41}$ En particular los movimientos sociales que ya sea bajo una forma de transversalidad o de "frente" reclamaban para sí un lugar en el armado kirchnerista y algunos, en particular Libres del Sur, veían con desconfianza cualquier apuesta que incluya a la estructura del Partido Justicialista
} 
quién vaya como candidato a presidente, la construcción que le debemos ofrecer a la sociedad argentina debe ser amplia, plural, que tenga proyección estratégica y sea un marco superador a lo que se ha construido hasta ahora. (...) Siempre digo, la gran virtud del Frepaso en los años finales de los '90 fue construir la alianza grande que les permitió llegar al gobierno, siendo oposición. Hoy la oposición se fija en construir una alianza chica. En ese caso, más allá de las circunstancias que le tocaron vivir, mucho tuvo que ver el Chacho en esa construcción. En esta etapa, en esto sí voy a ayudar, hay que construir una concertación -un frente, un espacioabsolutamente amplia, que le dé pluralidad y la posibilidad de generar un espacio superador para cualificar definitivamente la construcción de una alternativa estratégica en la Argentina." 42

El kirchnerismo trazó su estrategia electoral de cara al 2007 en un contexto de fortaleza propia y debilidad del resto de los actores del sistema político. La situación de la UCR es un indicador de esta fragmentación y dio sustento a la "Concertación Plural". Lesgart define a la Concertación plural como "un agrupamiento inorgánico que reúne a dirigentes políticos de distintas extracciones políticas (básicamente, a radicales y peronistas) afines y aliados al anterior gobierno de Néstor Kirchner (...). Con ella se arribaron a diferentes alianzas territoriales frente a las elecciones provinciales. Y en las nacionales, con esa Concertación Plural se armó la fórmula que reunió a Cristina Fernández de Kirchner (FPV) y a Julio Cobos («radical k») ${ }^{43}$ Según Rodríguez "la fórmula de la Concertación Plural, nuevo dispositivo electoral tendiente a superar el clivaje peronismo-antiperonismo" ${ }^{\prime 4}$. En efecto, en un contexto de sistema de partidos marcado por la territorialización partidaria y la fragmentación de los partidos nacionales, Kirchner desplegó una estrategia de alianzas políticas con referentes subnacionales, particularmente de la UCR. Si la transversalidad se proponía agrupar a cuadros dirigentes intermedios que se habían quedado "huérfanos" de liderazgos (y de partidos), la concertación buscaba una alianza con elites políticas con representación regional consolidada pero sin capacidad de superar la diáspora que significó el estallido del $2001 .^{45}$.

El resultado electoral arrojó la elección de la fórmula del Frente para la Victoria, la presencia de un radical, el ex gobernador de Mendoza, Julio C. Cobos es un indicio del modo en que la estrategia de la Concertación Plural se plasmó en el armado electoral ${ }^{46}$. El cambio sensible radica en que ya no se trata de la construcción de una nueva fuerza política transversal

42 Néstor Kirchner "Lo que diga sobre la reelección no me lo van a creer" entrevista al diario Página/12, 21 de mayo de 2006.

43 Lesgart, Cecilia. "Argentina 2007. Notas coyunturales sobre un año electoral." L'Ordinaire des Amériques 208-209 (2008), P. 229-254.

44 Rodríguez, Darío A. "Populismo y liderazgo en la democracia argentina: Un cruce comparativo entre el menemismo y el kirchnerismo." Postdata 19.2 (2014), p. 673

${ }^{45}$ En particular por su matiz partidocrático que buscó aglutinar con elites provinciales ligadas a la UCR. Pierre Ostiguy la emparento, en este sentido, con la Concertación chilena. El resultado fue un win - win. Para un estudio de la "Concertación Plural" en niveles subnacionales: Quilici, Federico D., and Fernando J. Rinaldi. La Constitución de la "Concertación Plural" en Catamarca, Río Negro y Neuquén: Desnacionalización y Fragmentación Política. Cuadernos UNSAM, Núm 30., 2007.

46 Según Clerici "la alianza nacional del PJ denominada Frente para la Victoria, que presenta la formula Cristina Fernández-Julio Cobos, tracciona a la mayoría de los PJ distritales a replicar la estrategia en sus alianzas para el legislativo nacional. Los aliados nacionales fueron los partidos Intransigente, Conservador Popular y Frente Grande, pero en muchos de los distritos donde la alianza fue, igualmente, Frente para la Victoria, pocos o ninguno de sus aliados nacionales estaba presente en la coalición mediante sus correlatos de distrito": Clerici, Paula. "Juegos de congruencia: las estrategias de alianzas electorales de la UCR y el PJ en Argentina (19832013)." Revista Uruguaya de Ciencia Política 25.2 (2016), p. 39 
sino de una renovación de los partidos tradicionales en una coalición entre las fuerzas políticas clásicas (PJ-UCR) con partidos menores aliados como el Partido Frente Grande, el Partido Intransigente, sectores del Partido Socialista, de la Democracia Cristiana, etc.

Esta estrategia requería de un control formal del Partido Justicialista, más allá que éste había quedado bajo la conducción informal del kirchnerismo luego de la victoria del 2005. Así, en enero de 2008, Kirchner comenzó una serie de reuniones para "reorganizar el PJ" que días más tarde se coronó en un acuerdo con Ricardo Lavagna (que había competido en las presidenciales de 2007 en alianza con sectores de la UCR), a principios de febrero, Kirchner declaraba "Con el doctor Lavagna coincidimos en la necesidad de reorganizar al justicialismo como un partido de centro progresista, respetando la diversidad interna y dando espacio a las distintas expresiones partidarias" ${ }^{47}$. Esta decisión de Kirchner de ocupar la presidencia del Partido Justicialista generó distintas reacciones en el arco transversal no partidario, en particular en los movimientos sociales. Prueba de ello es la reunión que Kirchner mantuvo con dirigentes de estos movimientos en los que expuso las razones de su decisión. Mientras algunos aliados como el Movimiento Evita (en la figura de Emilio Pérsico) apoyaron y se sumaron a la reorganización del partido, otros como Luis D'elia y Edgardo Depetris se mostraron abiertos a este viraje que fue cuestionado por "Libres del Sur" que un año más tarde abandonaría el espacio kirchnerista ${ }^{48}$

Este intento puede leerse en la clave de uno de los propósitos del kirchnerismo en lo que refiere a la reconfiguración del escenario político y del sistema de partidos. Allí el PJ podría ubicarse como núcleo de una concertación de centro-izquierda que deje un espacio de centroderecha para la alianza de sectores del peronismo y el radicalismo con la figura en ascenso de Mauricio Macri (quién había ganado las elecciones de la ciudad de Buenos Aires en 2007). Es decir no se trataba sólo de recomponer una fuerza sino de configurar un polo ideológico que influya en la totalidad del campo político, delimitando otros espacios (especialmente hacia la centro-derecha) y generando un nuevo sistema de partidos ${ }^{49}$

El conflicto desatado en marzo de 2008 a partir de la resolución 125que modificaba el esquema de retenciones por derechos de exportación de productos agrícolas (fundamentalmente la soja) en un contexto de expansión del precio de los commodities fue, sin dudas, un parteaguas en la política argentina ${ }^{50}$. Este conflicto entre el gobierno y las entidades agropecuarias (conocido como campo-gobierno) tuvo al menos tres efectos en lo concerniente a la estrategia política del kirchnerismo. En primer lugar, la configuración de un nuevo escenario simbólico en disputa que generó colectivos de identificación. Tanto el "nosotros" como el "ellos" (cualquiera que sea el contenido, condensado en "Gobierno-Campo"), se

\footnotetext{
47 “Acuerdo político de Kirchner y Lavagna para reorganizar el PJ” diario Clarin, 2 de marzo de 2008, edición on line (disponible: https://www.clarin.com/ediciones-anteriores/acuerdo-politico-kirchner-lavagna-reorganizarpj_0_SJWbgNAATKx.html)

${ }^{48}$ Sobre la relación de Libres del Sur con el kirchnerismo ver: Schuttenberg, Mauricio. La reconfiguración de las identidades "nacional populares": Los puentes discursivos para la inserción de tres tradiciones políticas en el espacio "transversal kirchnerista". Sociohistórica, (28), 41-73. 2011. También

49 Rodríguez, Darío. Cambios en la vida política argentina y la constitución de los liderazgos de Carlos Menem (1989-1995) y Néstor Kirchner (2003-2007). En Cheresky y Dabene (comp.) Ciudadanía y representación política, Argentina en perspectiva comparada. CLACSO-PROMETEO, Buenos Aires. 2012.

50 Para una aproximación al conflicto "Campo-gobierno" puede consultarse la compilación Aronskind, Ricardo \&Vommaro, Gabriel (comp.) Campos de batalla. Las rutas, los medios y las plazas en el nuevo conflicto agrario. Buenos Aires: UNGS-Prometeo. 2010.
} 
constituyeron como lugares de identificación y ordenaron binariamente el espacio de reconocimiento $^{51}$. La productividad identitaria del conflicto se evidenció en ambos bandos, la emergencia de un abigarramiento discursivo en el devenir kirchnerismo así como la constitución de un polo opositor más unificado (una especie de "Concertación plural opositora"). Por primera vez, desde mayo de 2003, emergían actores políticos abiertamente opositores con capacidad de acción colectiva y articulación política (la cual fue in crescendo a medida que avanzó el conflicto). El proceso de repolitización alcanzó una nueva fase donde no sólo se interpelaba al campo militante sino a amplios sectores de la sociedad y se confirmó una opinión púbica intensamente politizada en torno a un clivaje. El segundo efecto es la modificación de las alianzas constitutivas de la "Concertación Plural" oficialista, no sólo por el voto "no-positivo" del vicepresidente Julio C. Cobos, sino también por el corrimiento de otros sectores con los cuales el gobierno contaba como parte o como aliados circunstanciales, especialmente en las zonas de conflicto. Esto, como veremos, tendrá consecuencias en la táctica política de "ir a lo seguro" de cara a las elecciones de 2009. El tercer efecto fue la visibilización de actores que se hicieron presentes en el escenario, los grupos mediáticos y las organizaciones rurales: fundamentalmente la tradicional Sociedad Rural Argentina, así como sectores medios que encontraron en las redes sociales (articulado con acciones colectivas de protesta) un nuevo escenario de participación política.

\section{Volver al Partido Justicialista. Táctica post 2008}

La decisión de encabezar el Partido Justicialista, si bien tomada previamente al conflicto con el "Campo" se resignificó luego de desatada la beligerancia y la rápida inestabilidad de la Concertación Plural como plataforma para garantizar la gobernabilidad. Atrás habían quedado aquellas declaraciones de Néstor Kirchner en 2006:

-Yo no participo del pejotismo. Pude ser presidente del partido y no lo fui, no lo soy, ni lo seré. Pude haberme dedicado a armar una aceitada máquina partidaria y no lo hice. Tuve todas las condiciones para hacerlo, me ofrecieron todas las condiciones, aun gente que después me enfrentó. La construcción superadora va a permitir que los partidos se organicen. Si organizamos el mismo funcionamiento partidocrático interno que hubo hasta ahora corremos el riesgo de repetir los errores del pasado ${ }^{52}$.

La coyuntura reforzó la estrategia de Néstor Kirchner de asumir formalmente la conducción de Partido Justicialista como un modo de contribuir a la dirección de la estructura partidaria e impedir la proliferación de estrategias particulares a partir de un hecho inédito: la merma en la popularidad del gobierno derivado tanto de los resultados de la contienda con el "Campo" como por las consecuencias de la crisis internacional desatada en $2008^{53}$. El objetivo de ocupar el PJ para ponerlo como núcleo de una coalición de centro-izquierda se desplazó en

\footnotetext{
${ }^{51}$ Esto no implica desconocer el intento de "terceras posiciones" en el conflicto, pero precisamente la saturación binaria del espacio impidió la eficacia de estas intervenciones.

52 Néstor Kirchner, Op. Cit, 2006.

53 Tagina, María Luisa. "Elecciones de 2009 en Argentina: cambios en la distribución del poder y nuevos desafíos de cara a las presidenciales”. En Manuel Alcántara Sáez y María Laura Tagina (Eds.), América Latina: política y elecciones del bicentenario (2009- 2010), Madrid: Centro de Estudios Políticos y Constitucionales.
} 
pocos meses hacia una estrategia netamente defensiva que buscó evitar la masiva fuga de aliados y que otras elites partidarias periféricas tomen preponderancia en la definición de agendas parlamentarias y, fundamentalmente, tácticas electorales. Esta tensión/transición de la concertación plural hacia el retorno al partido se expresa en pasajes del breve discurso dado por CFK en el acto en el que Néstor Kirchner asumió la presidencia del partido.

"Así es que convocamos desde este espacio político a todos los argentinos, sin distinción de banderías, sin distinción de pertenencias, a debatir y a discutir en un marco democrático para profundizar la trasformación y el crecimiento para que siga dando trabajo a todos los argentinos"

"Quiero agradecer en esta tarde que ya anochece, la presencia de todos ustedes, de todos los hombres y mujeres que conforman el Consejo Nacional del Partido Justicialista, de todos los militantes que se han acercado hoy aquí, porque es en nombre de estos militantes donde se ha mantenido vivo el Partido, nuestra historia y nuestras tradiciones, También quiero convocar a la necesaria reconstrucción del sistema político argentino porque es necesario que todos, aún aquellos que tal vez están en las antípodas de nuestro pensamiento, puedan expresarse democráticamente a través de un partido político. Esta comprensión del ejercicio democrático en las diferencias de las ideas, es la que nos va a permitir construir la verdadera calidad institucional que tanto han reclamado y que todos debemos construir por respeto a la democracia, a las instituciones y, por sobre todas las cosas, a la voluntad popular." 54

La recomposición del Partido Justicialista incluyó a Juan Cabandié como Secretario de la Juventud y a Hugo Moyano (Secretario General de la CGT) como Vicepresidente segundo y Daniel Scioli (gobernador de la provincia de Buenos Aires) como Vicepresidente primero, además de otros gobernadores como Jorge Capitanich (Chaco) Sergio Urubarri (Entre Ríos) Juan Manuel Urtubey (Salta) José Luis Gioja (San Juan) Celso Jaque (Mendoza) Lucía Corpacci (Catamarca) y Walter Barrionuevo (Jujuy). La composición del secretariado -que funciona como lugar de reconociendo mucho más que como dispositivo de organización dado el funcionamiento fáctico del partido- es una muestra del marco de alianzas que se consolidó con los actores clásicos del justicialismo: sindicatos y gobernadores. A estos se le incorporaron dos actores novedosos provenientes de los años de movilización social: el hijo de desaparecidos Juan Cabandié (derechos humanos) y Emilio Pérsico del Movimiento Evita como secretario de relación con organizaciones sociales.

En un contexto defensivo, el kirchnerismo consolidó una estructura partidaria con mayoría de referentes con poder institucional propio y definió la táctica electoral de 2009 conocida como "candidaturas testimoniales" que consintió en incluir a dirigentes que se encontraban en funciones ejecutivas en la contienda legislativa ${ }^{55}$, las cuales además, se adelantaron cuatro meses en el cronograma electoral. La inclusión de candidatos con cargos vigentes (nacionales, provinciales y municipales) tuvo el objetivo de evitar que, ante un

54 Discurso de Cristian Fernández de Kirchner el 14 de mayo de 2008. Disponible en: https://www.casarosada.gob.ar/informacion/archivo/18293-blank-19750955

55 Burdman, Julio. "Alfas, ranas y testimoniales: la cultura política de las elecciones legislativas de medio término en Argentina”. Postdata, 15(1), 2010. En la provincia de Buenos Aires, además del gobernador Daniel Scioli y el Jefe de Gabinete Sergio Massa, participaron de las listas unos 45 jefes comunales. Al respecto ver: Piana, Ricardo Sebastián, and Noelia S. Baeza. "Candidatos a medida ¿Cómo se construyó el candidato que le ganó a los Kirchner?" Revista de la Facultad de Derecho y Ciencias Políticas 43.119 (2013): 773-800. 
escenario de opinión pública (y encuestas) desfavorable al gobierno, los líderes intermedios tuvieran incentivos para apostar a otras listas peronistas no kirchneristas como la liderada por el empresario Francisco De Narvaéz en la provincia de Buenos Aires. Precisamente en ese distrito -el principal- se concretó una derrota del oficialismo (con el propio Néstor Kirchner encabezó la lista a diputados) y a nivel nacional se produjo un retroceso en la performance electoral si se compara con 2005 y 2007. Según Tagina: "Considerando la totalidad de los distritos electorales, el Kirchnerismo perdió 20 bancas de Diputados y cuatro de Senadores" (2011:138), una cifra relevante que modificó la dinámica parlamentaria del período siguiente.

\section{El retorno de "lo nacional, popular y democrático": hacia las presidenciales de 2011}

La coyuntura de 2008 marcó la identidad kirchnerista en tanto constituyó una fase del momento experiencial de colectivos que se identificaron con el proyecto gubernamental a la vez que se expandió un espacio de representación desde lo "nacional y popular". En efecto, el conflicto con las patronales agrarias constituyó un enemigo que podía ser fácilmente ligado al viejo término de "oligarquía" y su vínculo con la dictadura cívico militar. Esto no significa que esta reemergencia del discurso nacional-popular no haya tenido antecedentes, desde sus comienzos el kircherismo actualizó dicha tradición, sus imaginarios, sus épicas y sus topografías militantes. La disputa contra el ALCA y el aval a movilizaciones en clave antiimperialista y latinoamericana, los conflictos con el Fondo Monetario Internacional y el enfrentamiento con sectores del capital trasnacional fueron realizadas invocando esta tradición ligada a la soberanía política y la independencia económica. Sin embargo, a partir del conflicto con el campo, el modo de funcionamiento del dispositivo kirchneristas asumió otro registro que desplazó interpelaciones de alta intensidad del campo militante al resto de la sociedad. Desde programas de televisión (como el caso emblemático de $6,7,8^{56}$ ), hasta colectivos de intelectuales (como "Carta Abierta" ${ }^{57}$ ) marcaron una nueva fase de dicursividadkirchnerista y de estrategias en este plano.

El conflicto, como se dijo, culminó con una clara derrota táctica del gobierno nacional coronada por el voto negativo del vice-presidente y generó una sensible baja en su popularidad, que sumado al contexto internacional adverso y, luego, la derrota electoral de 2009 llevó a algunos analistas a vaticinar el fin del kirchnerismo ${ }^{58}$. Algunas encuestas

56 “6,7,8" fue un programa de la TV Pública que fue adquiriendo un marcado tono oficialista a partir de una concepción de "periodismo militante". El programa se transformó en un espacio de coordinación de simpatizantes del gobierno nacional. Su página de Facebook, por ejemplo, cuenta con más de un millón de seguidores y los televidentes emprendieron acciones colectivas en apoyo al gobierno de Cristina Fernández de Kirchner.

57 "Carta Abierta" es un colectivo de intelectuales originado durante el conflicto entre el gobierno nacional y las entidades empresariales agropecuarias antes mencionado. En esta iniciativa confluyeron importantes figuras de la intelectualidad argentina proveniente del peronismo y de la izquierda que construyeron un espacio de apoyo al gobierno nacional. Mediante declaraciones (llamadas "cartas abiertas") este colectivo sentó posición en la opinión pública ante temas de la agenda política y generó un debate en el campo intelectual sobre el proceso político. Para un análisis de los intelectuales durante el kirchnerismo: Martín Retamozo, «Intelectuales, kirchnerismo y política. Una aproximación a los colectivos de intelectuales en Argentina», Nuevo Mundo Mundos Nuevos [En línea], Cuestiones del tiempo presente, 2012.

58 Svampa, Maristella. "The end of Kirchnerism." New Left Review 53.Sept.-Oct: 2008, 79-95 
mostraban que "a fines de 2009 el 57\% de los entrevistados manifestaban tener una imagen negativa y sólo el 21\%expresaba tener una imagen buena o muy buena, un año más tarde, a fines de 2010, estosporcentajes se revirtieron en exactamente la misma proporción (Poliarquía Consultores)." ${ }^{, 59}$. En un contexto de debilidad, el kirchnerismo inició una etapa identificada como "radicalización progresista" 60 "exacerbación nacional-popular" "reperonización" que incluyó "una audaz política de expansión de derechos" incluso que, como afirma Anunzziata 64 , no se encontraban explícitas en las "promesas" de campaña y, sin embargo, tuvieron un efecto de legitimación y repolitización del espacio público.

Como respuesta directa a la derrota electoral, y a las condiciones en que Francisco De Narvaez usufructuó para alzarse con la victoria, el ejecutivo promovió una la "Ley de Democratización de la Representación Política, la Transparencia y la Equidad Electoral (Ley $\mathrm{N}^{\circ}$ 26.571)" que cambió la regulación sobre el financiamiento de las campañas electorales y el sistema electoral. En otro orden, previo al cambio en la conformación del Congreso envió una ley crear el Sistema Integrado Previsional Argentino (SIPA) la ley 26.425/08 que implicaba la estatización de los fondos de las AFJP. Retomando la agenda de organizaciones de la sociedad civil, el gobierno nacional promovió la sanción de la ley 26.522 de "Servicios de Comunicación Audiovisual" en octubre de 2009. Asimismo, mediante el DNU 1602/09, creo la Asignación Universal por Hijo como parte de una reforma al régimen de asignaciones familiares, así como programas como el "Programa Ingreso Social con trabajo" que motorizó un plan de cooperativas denominado "Argentina Trabaja". Desde comienzos del año 2010 comenzó a ponerse en evidencia una recuperación en la imagen de la presidenta, en un contexto de crecimiento económico luego de la crisis del 2008. Por su parte, "los ganadores en las elecciones legislativas no pudieron constituirse en alternativas viables de gobierno, experimentado sus principales líderes una marcada erosión en sus niveles de apoyo."

La ofensiva del gobierno en el plano cultural se centró en los festejos del Bicentenario a partir de la promoción de actos, festivales y encuentros que congregaron a millones de personas en el marco de una épica nacional-popular ${ }^{66}$. Esto, a su vez, fue acompañado de una notable mejora en las condiciones económicas producto de la incipiente recuperación postcrisis internacional. En ese año, además, se promovieron leyes como la conocida como

\footnotetext{
${ }^{59}$ Catterberg y Palanza, 2012 Op. Cit., p.4

${ }^{60}$ Varesi, Gastón. (. Argentina 2002-2011: neodesarrollismo y radicalización progresista. Realidad Económica, 264, 2011, 33-59

${ }^{61}$ Svampa, Maristella. “Argentina, una década después: Del «que se vayan todos»a la exacerbación de lo nacionalpopular”. Nueva Sociedad, (235), 2011, 17-34

62 Rocca Rivarola, María Dolores. "' De Néstor y Cristina. De Perón y Evita". Reflexiones sobre lo acontecido con la militancia kirchnerista y la identidad peronista desde 2003 hasta hoy." Revista SAAP 9.1 (2015): 143-172.

63 Aboy Carlés, Gerardo "El declive del kirchnerismo y las mutaciones del peronismo." Nueva Sociedad 249 (2014) p. 6

64 Annunziata, Rocío. "Más allá de la promesa electoral. Repensar la representación en Argentina." Sudamérica: Revista de Ciencias Sociales 3 (2014): 137-154.

65 Catterberg, Gabriela, and Valeria Palanza. "Argentina: dispersión de la oposición y el auge de Cristina Fernández de Kirchner " Revista de ciencia política (Santiago) 32.1 (2012, p. 23

${ }^{66}$ González, Malala. "Configurar el relato: Estética y montaje de imágenes performáticas en los festejos del Bicentenario Nacional”. Anales del Instituto de Arte Americano e Investigaciones Estéticas. Mario J. Buschiazzo (Vol. 45, No. 2, 2015, pp. 119-132).
} 
"matrimonio igualitario" (Ley 26.618), de julio de 2010, introdujo modificaciones en el Código Civil para permitir la unión entre personas del mismo sexo ${ }^{67}$

En lo que refiere a la construcción de una fuerza propia, en este período adquiere una centralidad ineludible la "juventud" como sujeto tanto en el discurso kirchnerista como en la conformación de movimientos juveniles ${ }^{68}$. Como afirma Melina Vázquez ${ }^{69}$ el ingreso de la juventud fue promovido y autorizado por los "adultos" que identificaban a la juventud como "vanguardia" del proyecto. Este lugar preponderante se confirma con la paulatina centralidad de "La Cámpora" en el esquema de conducción del kirchnerismo y una serie de actos que se consolidaron en 2010 como el acto en el Luna Park "La juventud le habla a Néstor, Néstor le habla a la juventud" el 14/092010 donde participaron diferentes espacios juveniles: La Cámpora, Juventud Peronista; la JP Evita, la JP Descamisados, la JP Peronismo Militante, la Juventud Sindical Peronista ${ }^{70}$

El 27 de octubre de 2010 falleció repentinamente Néstor Kirchner, este acontecimiento significó la apertura de un tiempo extraordinario de conmoción en un importante sector de la población y la emergencia de un mito capaz de interpelar nuevos sectores y/o con una nueva intensidad en la configuración de un sujeto (y, como sabemos, "todo sujeto es un sujeto mítico", como dice Ernesto Laclau) Barbosa y Barros afirman que "él' simboliza a un fantasma que desafía la lógica de la presencia y se mantiene vivo en tanto porvenir, constituyéndose en uno de los significantes en los que se fundamentará la relegitimación hegemónica del kirchnerismo" "71. La muerte de Néstor Kirchner generó, según algunos autoresuna corriente de empatía hacia la presidenta ${ }^{72}$.

En un contexto favorecido, además, por la recuperación económica y de fragmentación de la oposición, las elecciones de octubre de 2011 arrojaron un resultado que en cierta medida sorprendió por la magnitud del triunfo de la fórmula CFK y Amado Boudou con el 54,11\% de los votos. La selección del vicepresidente -el ministro de Economía de CFK-, así como la fórmula Daniel Scioli-Gabriel Mariotto es un síntoma de la preponderancia del núcleo duro del kirchnerismo y la pretensión de continuidad de sus políticas. Boudou había sido uno de los mentores de la recuperación de los fondos en manos de las AFJP mientras que Mariotto había desempeñado un rol destacado en la gestación y aplicación de la Ley de Medios. Luego de asumir, el 10 de diciembre de 2011, CFK se dirigió a una multitud congregada en Plaza de Mayo

${ }^{67}$ Hiller, Renata. "Matrimonio igualitario y espacio público en Argentina” en Clericó, L. y Aldao M. -comp. Matrimonio Igualitario en la Argentina. Perspectivas sociales, políticas y jurídicas, Buenos Aires: Eudeba. 2010.

${ }^{68}$ Larrondo, Marina. "El Discurso Político Kirchnerista hacia la juventud en contextos de actos de militancia". Astrolabio, (11). 2013. Esto, por supuesto, no implica la inexistencia de activismo juvenil previo al kirchnerismo. Movimientos sociales de los años noventa, movimientos de derechos humanos como HIJOS (de desaparecidos) y el movimiento estudiantil tuvieron a jóvenes como protagonistas, sin embargo, bajo el kirchnerismo el lugar de lo juvenil adquiere rasgos específicos como sujeto político y referencia discursiva.

${ }^{69}$ Vázquez, Melina. "En torno a la construcción de la juventud como causa pública durante el kirchnerismo: principios de adhesión, participación y reconocimiento." Revista Argentina de Estudios de Juventud [En línea], 1.7 (2013)

${ }^{70}$ Flax, Rocío. "La caracterización de la juventud peronista en el discurso de Cristina Fernández de Kirchner. Cadernos de Linguagem e Sociedade, 16(1), 2015, 61-80

71 Barbosa, Sebastián., \& Barros, Eduardo. "Los senderos del tercer Kirchnerismo: Equilibrio económico, estabilización política y profundización social”. Revista Sul-Americana de Ciência Política, 1(1), 2013:40

${ }^{72}$ Catterberg y Palanza, Ob. Cit. 
Quiero agradecerles a todos los jóvenes de todas las agrupaciones y movimientos sociales de la patria, que han sido la verdadera vanguardia de este Gobierno en sus momentos más difíciles. Quiero también agradecerles a todos los trabajadores de la patria, porque no hay diferencia entre jóvenes y trabajadores, todos luchan por un país más justo, más libre y más igualitario Yo no quiero extenderme más porque sé que ha sido un día muy caluroso y me han hecho "el aguante" como solamente lo saben hacer ustedes en una Plaza. Siempre haciendo "el aguante", gracias y, además, vamos los descamisados, vamos el Movimiento Evita, vamos los Martín Fierro, vamos La Cámpora, vamos todos, todos juntos con los trabajadores.

La alocución pone de manifiesto el lugar de la movilización plebiscitaria que bajo la idea de "aguante" o "bancar" marcó el período y constituyó una forma de representación delegativa de alta intensidad.

\section{"Unidos y organizados". La fuerza propia. Entre la identidad, la gestión y la ineficacia.}

A partir de triunfo electoral del 2011 se abrió un período que algunos autores llamaron "tercer kirchnerismo" "73. La promesa de "sintonía fina" nominaba una agenda heterogénea que refería, en particular, a los desafíos de la gestión luego de la contundente victoria electoral y un escenario con problemas a resolver como la inflación, la restricción externa, el déficit fiscal yel aprovechamiento de los recursos energéticos. En este sentido pueden leerse una serie de medidas que se sucedieron en el 2012, desde la devaluación y la restricción a la compra de divisas extranjeras hasta la nacionalización de YPF.

En abril de 2012 se puso en escena una nueva estrategia de construcción política en el kirchnerismo, 27 de abril, un conjunto de organizaciones kirchneristascomo la Corriente Nacional de la Militancia, La Cámpora, el Movimiento Evita, El Frente Transversal Nacional y Popular, entre otras, convocaron a un acto en la cancha de Vélez bajo la consigna "Unidos y Organizados" en los que se privilegió la movilización de organizaciones propias por sobre la estructura del Partido Justicialista (tanto en su vertiente de intendentes como organizaciones sindicales). Al respecto es sintomática la apertura del discurso de CFK:

Este maravilloso acto que vinieron a proponerme los compañeros del Movimiento Evita y de La Cámpora allá por febrero era un acto que lo querían hacer el 11 de marzo" y yo les dije: "compañeros el 11 de marzo es un hito histórico de la patria. Lo es en mi historia política, fue la primera vez que pude votar, fui una militante de aquellos años, pero sin lugar a dudas sin el protagonismo que podía influir en el curso de esos acontecimientos vertiginosos. Vertiginosos y terribles también de aquella época. Dije entonces: "¿por qué no hacerlo el 27 de abril cuando comenzamos nosotros mismos a construir a partir de nuestras convicciones históricas, de nuestros principios políticos una historia que estamos escribiendo nosotros mismo y que jamás permitiremos que la vuelvan a escribir desde afuera o desde intereses contrarios a los de la patria?"74.

\footnotetext{
${ }^{73}$ Barbbosa y Barros, Op. Cit.

${ }^{74}$ Discurso de Cristina Fernández de Kirchner 27 de abril de 2012.
} 
Quedaba claro, entonces, que el desplazamiento de las efemérides del peronismo hacia el kirchnerismo tenía un componente político, como así también "el proceso de mutua contaminación entre particularidad y universalidad", kirchnerismo plasmada en lo nominal de las organizaciones convocantes (Movimiento Evita y La Cámpora) tanto como en los cánticos que establecen la polifonía subordinada de un acto (Patria si, colonia no!). La referencia a "Unidos y Organizados", también es una obvia alusión al "Unidos o dominados" "76, sirvió como espacio de coordinación de un conjunto de organizaciones (barriales, culturales, partidarias) pero no se plasmó formalmente como instancia orgánica. Organizaciones como el Movimiento Evita, por ejemplo, no tardaron en ubicarse al margen del espacio para coordinar en el espacio kirchnerista preservando su autonomía.

El espacio funcionó como ámbito de coordinación y lugar de enunciación kirchnerista en un contexto en que La Cámpora adquiría mayor prominencia en el dispositivo oficial. La puesta en escena a partir de los "patios militantes" y la consolidación de la "juventud" como referencia central del discurso de Cristina marcó la fase del ciclo. La gramática política kirchnerista en este período es particularmente compleja porque combina una expansión horizontal (cuasi rizomática) con el vínculo vertical y jerárquico del liderazgo de CFK. El resultado es una combinación de productividad de nuevas organizaciones de diverso tipo y, a la vez, centralización de las tomas de decisiones tanto a nivel de gestión como de estrategia. En efecto, de los cientos de organizaciones "kirchneristas" (estudiantiles, culturales, territoriales, políticas) sólo una ("La Cámpora") ha sido pergeñada por el núcleo del kirchnerismo "desde arriba hacia abajo". Notablemente, este momento de autopoiesis organizativa se articula con una concentración de las decisiones políticas (tanto de políticas públicas como de estrategias electorales) en la figura presidencial y la consolidación de un modo de movilización top-down con que los estudios norteamericanos han caracterizado a los movimientos "populistas" 77

El ejercicio de la conducción política derivó en pocos espacios orgánicos de renovación, en este sentido "la concentración del poder que ha tenido el kirchnerismo a lo largo de la última década no ha generado hasta ahora posibles sucesores aceptados por todo el espacio, y la única dirigente hoy acatada por el conjunto deberá abandonar el gobierno a fines de $2015^{\prime 78}$. Esto generó problemas de estrategia hacia las elecciones intermedias de 2013. En un contexto socio-económico poco favorable por factores internos y restricciones externas, el año 2012 también fue escenario tanto de una serie de protestas de sectores medios opositores como de un creciente malestar en buena parte del sindicalismo que rompió con la alianza con el gobierno en el marco de la expansión de demandas de los sectores asalariados sindicalizados en torno a la presión impositiva sobre el salario. Esto, a su vez, ponía en evidencia una disputa tanto por la representación de los trabajadores como por la reivindicación del peronismo.

\footnotetext{
${ }^{75}$ Laclau, Ernesto. "La democracia y el problema del poder”, en Actuel Marx, ¿Pensamiento único en filosofía política?, Buenos Aires, K\&ai Ediciones. 2001, p. 189.

${ }^{76}$ Una célebre frase del General Perón a principios de los años 50 en el que planteaba que el año 2000 encontraría a los países de Sudamérica "unidos o dominados"

77 Ver: Roberts, Kenneth M. "Neoliberalism and the transformation of populism in Latin America: the Peruvian case." World politics48.1 (1995): 82-116; Weyland, Kurt. "The threat from the populist left." Journal of Democracy 24.3 (2013): 18-32; Levitsky, Steven, and Kenneth M. Roberts, eds. The resurgence of the Latin American left. JHU Press, 2013.

78 Aboy Carlés, 2014. Op. Cit., p. 6
} 
Mientras que el gobierno nacional acusaba a los dirigentes sindicales de ser representantes corporativos, se adjudicaba la posibilidad de representación de la totalidad de los trabajadores, a la vez que asumía el rol de coordinación de diferentes sectores (incluso empresariales).

Sergio Massa, ex jefe de jefe de Gabinete de CFK comenzó a capitalizar las preferencias opositoras y a lograr acuerdos con intendentes peronistas de la provincia de Buenos Aires, fuerzas opositoras como el PRO de Mauricio Macri, sectores sindicales y empresariales (en especial la UIA). La candidatura de Martín Insaurralde, de un presunto perfil similar al de Sergio Massa, no logró ser una oferta lo suficientemente atractiva y muchos dirigentes -frente a la hipótesis del fin del kirchnerismo o el "poskirchnerismo"- decidieron "jugar" para el Frente Renovador. Incluso, como afirma Tegina ${ }^{79}$ muchos líderes locales llamaron a cortar boleta luego de que el resultado de las PASO de agosto mostrara una significativa ventaja del candidato no-kirchnerista. Con la posibilidad cerrada por disposición constitucional, la única alternativa para un tercer mandado de CFK pasaba por una reforma de la Carta Magna que, si bien nunca fue avalada abiertamente por figuras del ejecutivo, sí fue insinuada por cuadros ligados al gobierno, periodistas opositores y analistas políticos, el kirchnerismo se concentró en la gestión. A partir del resultado las elecciones de 2013, según García Delgado ${ }^{80}$ se evidencia un desplazamiento desde la "sintonía fina" hacia la "estabilización”, que implicó un conjunto de medidas macroeconómicas en torno al tipo de cambio y políticas de precios (como "precios cuidados") y ciertas políticas públicas (PROGRESAR. Créditos Pro.Cre.Ar) como estrategia que contribuía al "objetivo residual" como lo llaman Gerchunoff y Kacef ${ }^{81}$, de llegar al final del mandato sin una crisis y, a partir de ello, mejorar perspectivas de una sucesión electoral.

Ahora bien, si en las elecciones de 2013 Sergio Massa quedó posicionado como un referente de la oposición, la estrategia de otra parte de las fuerzas políticas se mostró eficaz, en particular por la Alianza entre los sectores de centro-derecha nucleados en torno a la figura de Mauricio Macri en el PRO, los sectores conservadores de la UCR que vencieron en la puja partidaria y la Coalición Cívica conducida por Elisa Carrió. El descontento de parte de la ciudadanía encontró dos espacios de representación en la centro-derecha, uno con raigambre peronista y otro que en buena medida prescindía de esa tradición. La derrota electoral, como muestra Tegina ${ }^{82}$, no se tradujo en una reducción sensible en la conformación de las cámaras legislativas pero sí un duro golpe político para la fuerza gobernante.

De cara a las elecciones de 2015 y ante la ausencia de candidatos "naturales" en particular a nivel nacional, CFK se ubicó como veto player informal en el armado de las listas en los principales distritos. De igual manera, emergió la consigna "El candidato es el proyecto" en voces de referentes de La Cámpora como Mariano Recalde (en el diario Página 12 del 8/3/05) y Axel Kiciloff (en el Diario Crónica del 21/6/05). Para Anunzziatta "proyecto" es "una narrativa que se construye retrospectivamente y que, por lo tanto, para los actores involucrados

\footnotetext{
79 Tagina, María Luisa. Las Elecciones Legislativas 2013 en Argentina. Revista Latinoamericana de Política Comparada, 45. 2014.

${ }^{80}$ García Delgado, Daniel. "De la agenda de sintonía fina a la de estabilización: la lucha por el modelo". Revista Estado y Políticas Públicas No 2. 2014. Pp.15-18

81 Gerchunoff, Pablo, and Osvaldo Kacef. "¿Y ahora qué hacemos?": la economía política del Kirchnerismo." Documentos de trabajo (IELAT, Instituto Universitario de Investigación en Estudios Latinoamericanos) 87 (2016): 1-59.

82 Tegina 2014, Op. Cit.
} 
el proyecto sólo se va haciendo inteligible como una sucesiónde decisiones que se reinscriben en él a medida que se toman" ${ }^{\prime 83}$ Con la arena electoral dominando la escena y sin candidatos propios, varios sectores lanzaron la candidatura a presidente con intenciones de representar al FPV. Por un lado, Daniel Scioli con buena llegada a sus pares gobernadores y recelos en sectores del kirchnerismo, por otro Uribarri -gobernador de Entre Ríos- Florencio Randazzo ministro del interior y transporte- y Jorge Taiana, impulsado por el Movimiento Evita. Con candidaturas poco instaladas, Uribarri y Taiana bajaron sus pretensiones y la contienda parecía encaminarse a una compulsa entre Scioli y Randazzo, sin embargo, la inclusión en la fórmula de Carlos Zannini, un cuadro de la "mesa chica" del kirchnerismo y uno de los principales asesores de CFK, ofició de guiño a la construcción del gobernador en detrimento del ministro, quien dimitió de su candidatura con una carta de lealtad hacia la presidenta.

En la provincia de Buenos Aires se enfrentaron en las PASO dos listas, una integrada por el ex presidente de la Cámara de Diputados de la Nación, Julián Domínguez y el intendente de La Matanza, Fernando Espinoza, la otra por el ex Jefe de Gabinete Aníbal Fernández y el referente de Nuevo Encuentro, Martín Sabatella. Esta última fórmula se impuso y finalmente se presentó en las elecciones generales de octubre de 2015 en la que cayó derrotada por la encabezada por María Eugenia Vidal, una de las mayores sorpresas de la elección.

\section{El Frente Ciudadano. Ciudadanía, partido y movimiento. 2016-2017}

"Muchas gracias por este regalo que me dan de bienvenida" inició CFK su alocución frente a seguidores que la esperaban fuera de los tribunales de Comodoro Py el 13 de abril de 2016 luego de cumplir con una citación del poder judicial. Ahora bien ¿̇a dónde se había ido luego del 9 de diciembre de 2015? ¿A dónde volvía? Más allá de su retiro en El Calafate, la hipótesis de esta sección es que CFK marcó su bienvenida a los nuevos tiempos de la política argentina: el kirchnerismo poskirchnerista. En esa ocasión, su primera aparición pública fuera del poder ejecutivo, CFK convocó a la conformación de un "Frente Ciudadano" cuya materialización electoral tendrá lugar en los comicios legislativos de medio término al año siguiente

"Y les propongo esencialmente conformar un gran frente ciudadano. Un frente ciudadano en el cual no se le pregunte a nadie a quién votó, ni de qué partido es, ni en qué sindicato está, o si es trabajador informal, o formal, jubilado, no jubilado, si paga ganancias o no paga ganancias, que no se le pregunte nada de eso. Que se le pregunte cómo le está yendo, si le está yendo mejor que antes o peor. Entonces ese es el punto de unidad de los argentinos: reclamar por los derechos que les han arrebatado" (...) "ese frente patriótico que debe estar integrado por ciudadanos sin afiliación, agrupados en ONGs, asociaciones sociales, religiosas, de cualquier tipo" (...) "la única organización de la que formé parte fue del Poder Ejecutivo Nacional como su titular, elegida democráticamente por la voluntad de los argentinos en dos oportunidades

83 Anuzziata, Rocío "El candidato es el proyecto": la construcción de la narrativa kirchnerista en Riorda, Mario y Rincón, Omar (eds): Comunicación gubernamental en acción: narrativas presidenciales y mitos de gobierno, Buenos Aires, Biblos, 2016: 112 
consecutivas, primero con el 46\% de los votos, y luego con el 54\%. Ah sí, también les dije que formo parte de otra organización: el Partido Justicialista." 84

El discurso de CFK en Comodoro Py, fue el primero público del kirchnerismo poskirchnerista, en un escenario en que comenzó a perfilarse, además, un cambio de estética y regla. Por un lado, la relación directa entre líder y ciudadanía que se confirma en el mismo momento que se la impugna. Es decir, la líder enunciando su prescindencia, algo que estuvo presente como rasgo en el último acto en funciones. El 9 de diciembre de 2015 CFK se dirigió al público que se había dado cita en Plaza de Mayo.

"cada de los 42 millones de argentinos, tiene un dirigente adentro y que cuando cada uno de ustedes, cada uno de esos 42 millones de argentinos sienta que aquellos en los que confió y depositó su voto, lo traicionaron, tome su bandera y sepa que él es el dirigente de su destino y el constructor de su vida, que esto es lo más grande que le he dado al pueblo argentino: el empoderamiento popular, el empoderamiento ciudadano, el empoderamiento de las libertades, el empoderamiento de los derechos ${ }^{85}$.

Por otro lado, ya no son las organizaciones las que median la relación entre ciudadanos y la representación política. Si la fallida experiencia de Unidos y Organizados procuraba la consolidación de las mediaciones, la ciudadanización del movimiento diluye la potencia del antagonismo (el cual se reactualiza en el segundo orden, es decir sobre la matriz Ellos-ajuste vs nosotros pueblo) pero en el lenguaje de los derechos ciudadanos.

Si el kirchnerismo fue una fuerza que se conformó en el poder instituido, el desplazamiento al espacio de la oposición constituyó un nuevo lugar de enunciación y un cambio en el campo de las prácticas potenciales. Es evidente que esta situación genera nuevas condiciones del hacer política ya que se diluye la responsabilidad de garantizar gobernabilidad y ejercer la gestión a nivel nacional (aunque no a niveles subnacionales). Esto reposiciona las otras dos dimensiones a las que hicimos referencia: la conformación de la fuerza propia y la estrategia electoral. Con las elecciones aún lejos, a principios de 2016 CFK enuncia la idea de un Frente Ciudadano como táctica de acumulación. Esto, por supuesto, no implica una ruptura con otras formas políticas (partidarias, sindicales, movimientistas) pero sí la subordinación a un tipo de construcción en clave de derechos ciudadanos. Esto generó ciertas reservas en los sectores identificados con el kirchnerismos que centran su concepción política en la idea de pueblo. No fue casualidad que una semana después, en un acto en el ND Ateneo (un teatro porteño), CFK haya convocado a cuadros de los movimientos sociales. Allí expresó:

"mi intención en el día de hoy era dirigirme a todos ustedes para convocarlos a una construcción y a una organización que tiene que ver con la conformación de un Frente Ciudadano. Algunos compañeros, entre ellos algunos muy cercanos a mí, me dicen ¿por qué ciudadano? Cierto, suena por ahí... algunos sectores ¿tal vez sea liberal? No, al concepto, no, no es liberal. Ser ciudadano es fundamentalmente poder ejercer la libertad de qué vida se quiere tener, y para poder ejercer la libertad de qué vida se quiere tener, tenés que tener un trabajo que

\footnotetext{
${ }^{84}$ Cristina Fernández de Kirchner. Discurso del 13 de abril de 2016.

${ }^{85}$ Cristina Fernández de Kirchner. Discurso del 9 de diciembre de 2015.
} 
te permita vivir dignamente, proporcionarte una vivienda, estudio para tus hijos y mínimamente vacaciones una vez al año"86

En esta nueva fase de construcción, la estrategia discursiva pivotea en la recuperación de la tradición nacional-popular, pero en una clave, en cierto modo, posperonista

"los peronistas que no somos los únicos que hemos contribuido a la construcción de este proyecto, tenemos que entenderlo, aceptarlo, porque es además... está en nuestro origen. El peronismo en el 45 no existía, existía Perón, pero no existía el peronismo. Existía multiplicidad de dirigentes de distintos partidos, extracciones, que iban desde conservadores pasando por radicales, por comunistas, por socialistas, por curas, por católicos, anarquistas, que conformaron... Por eso la primera regla de ese Frente Ciudadano es el no sectarismo y el no creerse el ombligo y la columna vertebral de vaya a ser qué cosa. Basta con ese verso de somos la columna vertebral" 87

Sin embargo, discursivamente, la estrategia de un nuevo espacio político nacionalpopular post-peronista incluye el abordaje de un viejo adagio del General Perón "la organización vence al tiempo". En sus palabras:

"ese movimiento ciudadano que yo sueño, porque, para finalizar, una de las cosas que siempre me desveló y que he visto en estos tiempos de análisis y de reflexión, es el sí no de los movimientos nacionales y populares, los avances y los retrocesos, producto que los liderazgos de esos movimientos políticos y sociales no pudieron generar, no pudieron parirse a sí mismos como liderazgos en una organización que no descansara en una, dos o tres personas, sino que descansara en una orgánica. Yo ayer lo comparaba con la Iglesia, cuando estaba con los curas los vi ahí y de repente lo vi y dije: se pudo organizar una Iglesia que dura dos mil años a partir de Cristo. Por favor, nadie quiera compararse con Cristo, yo creo que Cristo además... no sé si decirlo. No, no sé si era peronista pero a mí me parece que..." 88

Ahora bien ¿Qué hacer con el Partido Justicialista en este contexto? Un dilema similar, pero en un contexto completamente diferente al planteado en el 2005 cuando el kirchnerismo le arrebató "corriendo por afuera" el liderazgo del peronismo de la provincia de Buenos Aires a los sectores ligados a Eduardo Duhalde. Como vimos, la conducción desde el Ejecutivo nacional y provincial primero y luego la asunción de lugares en la directiva partidaria marcó que el instrumento electoral del kirchnerismo sea el Frente para la Victoria en el Partido Justicialista. Sin embargo, en el contexto de 2017, dada las nuevas reglas electorales, inscribir la candidatura de CFK dentro del Partido Justicialista implicaba habilitar la contienda interna en las elecciones Primarias Abiertas Simultáneas y Obligatorias (PASO) al sector que impulsaba a Florencio Randazzo. La decisión táctica fue participar de la contienda por fuera del espacio formal del Partido Justicialista. Sin embargo, un repaso a la conformación de las listas a senadores y diputados del principal distrito muestra la presencia medular de cuadros provenientes y persistentes en la estructura del Partido Justicialista tanto a nivel nacional como provincial.

\footnotetext{
${ }^{86}$ Cristina Fernández de Kirchner. Discurso del 20 de abril de 2016

${ }^{87}$ Ibídem.

${ }^{88}$ Ibídem.
} 
Candidatos de Unidad Ciudadana en la Provincia de Buenos Aires

\begin{tabular}{|l|l|}
\hline Senadores Nacionales & \\
\hline $\begin{array}{l}\text { Cristina Fernández de } \\
\text { Kirchner (titular) }\end{array}$ & Ex presidenta (2007-2011 y 2011-2015) FPV- PJ \\
\hline Jorge Taiana (titular) & Ex Canciller. Dirigente del PJ desde 1972. FPV-PJ \\
\hline $\begin{array}{l}\text { Héctor Recalde } \\
\text { (suplente) }\end{array}$ & $\begin{array}{l}\text { Jefe del Bloque de Diputados del FPV-PJ (desde 2015) - Abogado } \\
\text { laboralista ligado de la CGT }\end{array}$ \\
\hline $\begin{array}{l}\text { Juliana Di Tulio } \\
\text { (suplente) }\end{array}$ & $\begin{array}{l}\text { Jefa del bloque de diputados FPV-PJ (2013-2015) Diputada desde } \\
\text { 2005. }\end{array}$ \\
\hline
\end{tabular}

\begin{tabular}{|l|l|}
\hline Diputados Nacionales & \\
\hline 1. Fernanda Vallejos & $\begin{array}{l}\text { Economista. Asesora de la cámara de de Diputados. Con pasado de } \\
\text { militante estudiantil del Frente Grande, luego en la MaKro y el } \\
\text { Ministerio de Economía }\end{array}$ \\
\hline 2 Roberto Salvarezza & \multicolumn{1}{|c|}{ Extrapartidario - Científico. Ex Presidente del CONICET } \\
\hline 3 Fernando Espinoza & $\begin{array}{l}\text { PJ- La Matanza (Ex Intendente) Presidente del Partido Justicialista a } \\
\text { nivel provincial) }\end{array}$ \\
\hline 5 Vanesa Siley & $\begin{array}{l}\text { CGT-Peronismo - Sindicalista. Secretaria general de SITRAJU } \\
\text { (Sindicato de Trabajadores Judiciales) }\end{array}$ \\
\hline 6 Hugo Yaski & $\begin{array}{l}\text { PJ - FPV (Ex gobernador) } \\
\text { Ce los trabajadores }\end{array}$ \\
\hline 7 Monica Macha & Nuevo Encuentro - FPV (Ex legisladora provincial) \\
\hline 9 Leopoldo Moreau & Movimiento Alfonsinista. Radical K. Ex Diputado por la UCR \\
\hline 10 Walter Correa & La Cámpora - FPV (Ex funcionaria) La Cámpora \\
\hline 11 Magdalena Sierra & PJ- Avellaneda (Ex legisladora provincial) \\
\hline 12 Horacio Pietragalla & $\begin{array}{l}\text { Nieto recuperado por Abuelas de plaza de Mayo. Ex diputado nacional } \\
\text { por el FPV-PJ }\end{array}$ \\
\hline 13 Laura Russo & PJ- Escobar (Ex legisladora provincial) \\
\hline 14 Héctor "Gallego" & PJ - Peronismo Militante \\
\hline 15 Agustina Propato & FPV- PJ (Ex Funcionaria del Ministerio de Seguridad) \\
\hline
\end{tabular}

Unidad Ciudadana obtuvo el $37.25 \%$ de los votos y fue derrotada por CAMBIEMOS que obtuvo 41.38 mientras que Sergio Massa el 11.32 y Florencio Randazzo-candidato oficial del Partido Justicialista- el 5.31. En su intervención a poco de conocerse las tendencias definitivas, Cristina Fernández de Kirchner expresó: "Unidad Ciudadana ha venido para quedarse. Seremos la base, no la totalidad, de la construcción alternativa a este gobierno. Sabemos que el voto recibido es fundacional, una semilla de esperanza que vamos a regar 
todos los días" (...) "Aquí no se termina nada. Aquí empieza todo. Mañana empieza el trabajo de Unidad Ciudadana" 89 .

\section{Conclusiones (provisorias)}

A poco de su asunción, Néstor Kirchner enfrentó desafíos en diferentes escenarios. Por un lado, construir una fuerza propia con poder irradiado desde el ejecutivo y que cuaje en el campo de la movilización social, el poder legislativo y en la propia capacidad del gobierno para garantizar gobernabilidad. Por otro, la búsqueda de una reconfiguración del sistema político argentino afectado por la crisis del 2001 en un contexto de transformación de las identidades políticas clásicas. La primera estrategia, la "transversalidad", que como vimos incluye un conjunto de tácticas, buscó la conformación de un nuevo sujeto que se nutriera de tradiciones diversas para dar lugar a una articulación. Articulación que, por definición, produce algo nuevo y diferente a los elementos que ingresan en ese proceso. Allí radica la diferencia con la estrategia siguiente: la "concertación plural", que funcionó para las elecciones presidenciales de 2007 como una alianza con sectores de la UCR con control territorial. Sin embargo, una no puede comprenderse una sin la otra ya que transversalidad funcionó de polo para disputar la conducción del movimiento nacional peronista que luego permitió la construcción de la Concertación como espacio electoral.

El conflicto con las patronales agrarias cambió la dinámica política y las estrategias. En un contexto de avance de los adversarios el kirchnerismo ocupó una trinchera de la cual se había mantenido distante: el Partido Justicialista. En efecto la asunción de Néstor Kirchner como presidente del partido en 2008 marcó una estrategia de repliegue que, a la vez, permitía bloquear el acceso a ese recurso organizativo por parte de otras elites partidarias.

Luego de la derrota electoral del 2009 vino un proceso de acumulación de capital político por parte de CFK, tanto por un contexto de mejora en la actividad económica postcrisis mundial, como por un conjunto de políticas públicas y la muerte de Néstor Kirchner. Estos factores explican el abultado triunfo en las elecciones de 2011 bajo un liderazgo absoluto de la presidenta. Luego de la victoria electoral se abrió otra etapa en lo que concierne a la estrategia: la búsqueda de fuerza propia ante el déficit organizativo. "Unidos y organizados" fue el fugaz intento de construir un espacio de coordinación de organizaciones kirchneristas que ponían en acto las decisiones políticas de CFK. Sin embargo, este espacio no logró institucionalizarse y pronto se diluyó. Ya en las elecciones legislativas de 2013 el espacio languideciente acompañó una táctica electoral que fue derrotada. Posteriormente candidatura de Daniel Scioli, secundado por un cuadro de conducción del kirchnerismo como Carlos Zanini fue acompañada sin demasiado énfasis y concluyó en una derrota electoral en las presidenciales de 2015.

Esto muestra un rasgo del kirchnerismo: su bajo nivel de organización y su tensa relación con la estructura partidaria. En 2016, frente a los tribunales CFK, luego de prestar declaración, refería: "le contesté que la única organización de la que formé parte fue del Poder Ejecutivo Nacional como su titular, elegida democráticamente por la voluntad de los argentinos en dos oportunidades consecutivas, primero con el 46\% de los votos, y luego con el

\footnotetext{
${ }^{89}$ Cristina Fernández de Kirchner. Discurso del 22 de octubre de 2017.
} 
54\%. Ah sí, también les dije que formo parte de otra organización: el Partido Justicialista" ${ }^{90}$. En efecto, los lugares de promoción de la coordinación política que atravesaron al kirchnerismo: el ejecutivo, el partido y el liderazgo, adquirieron dinámicas inestables sobredeterminadas por este el último. La forma de la representación política del kirchnerismo asumió complejidades por el juego de cercanía y delegación, así como los efectos que la representación (en el sentido especular) ejerce sobre los representados que encuentran en esa imagen la posibilidad de articulaciones horizontales.

El escenario en 2016 -y hacia las elecciones legislativas 2017- estuvo marcado, para esta fuerza por la liberación de la responsabilidad de garantizar las condiciones de gobernabilidad y tomar decisiones de política pública. Así, el foco se posicionó en la construcción de una nueva fuerza política. Si el Frente para la Victoria promovió inicialmente un intento de renovación del campo político mediante la transversalidad y luego impulsó la alianza de organizaciones bajo la idea de "Concertación", Unidad Ciudadana atisba una lógica distinta de construcción de representatividad: una representación en clave ciudadana escasamente mediada por organizaciones. La estrategia de Unidad Ciudadana, si bien incipiente, presenta novedades en el énfasis en tres aspectos. En la forma de representación centrada en la figura espectral de CFK, en el bajo nivel de organización novedosa y la referencia a la ciudadanía sobre la gramática plebeya. Esto genera incógnitas sobre tres instancias asociadas: el proceso identitario, las formas organizativas y la capacidad de acción tanto en el terreno electoral como de la movilización social. El dilema del actor y el sujeto sobrevuela esta nueva iniciativa que pone en tensión a la ciudadanía y al pueblo.

En un viejo y exquisito trabajo Guillermo $\mathrm{C} ` d o n n e l l^{91}$ proponía tres mediaciones que, a su juicio, el Estado capitalista instauraba como un modo de gestionar una comunidad política basada en la desigualdad fundamental entre quienes poseen los medios de producción y quienes venden su fuerza de trabajo: la nación, la ciudadanía y el pueblo. O'donnell argumentaba que el Estado capitalista admitía mayor espacio para la mediación ciudadana que para la mediación popular. Esto porque mientras la ciudadanía propone una relación abstracta con la comunidad bajo la forma "estado de derecho", mientras que existe una posibilidad de articulación entre lo popular y el nudo antagónico del orden social capitalista: las clases. En efecto, la invocación al pueblo como referente del Estado capitalista puede entrar en contradicción cuando lo popular asume demandas de clase que afectan al corazón del orden capitalista. En la actualidad este debate de las contradicciones, los antagonismos y los sujetos políticos de las democracias contemporáneas tienen otros escenarios teóricos, sin embargo, las preguntas y los desafíos políticos son persistentes. La invocación a la "ciudadanía" de Unidad Ciudadana supone un modo de defensivo de resguardo de ciertos derechos adquiridos en el ciclo político kirchnerista y encuentra limitantes en su anclado como proceso identitario y de subjetividad política. Esto implica pensar los alcances de los modos de subjetividad ciudadana y subjetividad popular.

El futuro del kirchnerismo como fuerza política se encuentra en un momento crucial. Fuera del poder ejecutivo y desplazado del Partido Justicialista, se encuentra vertebrado en torno al liderazgo espectral de CFK, un entramado de representación parlamentaria y un

${ }^{90}$ Cristina Fernández de Kirchner. Discurso del 13 de abril de 2016.

91 O'donnell, Guillermo. “Apuntes para una teoría del Estado”. Revista Mexicana de Sociología, 1978, Pp. 1157-1199. 
espacio simbólico capaz de generar fuertes procesos de identificación. El proceso político de cara a las elecciones presidenciales de 2019 marcará nuevos tiempos para el kirchnerismo y el dilema de constituir una fuerza autónoma, participar de un frente único o aportar a la reconstrucción del peronismo como principal fuerza de un frente popular.

Bibliografía

- Aboy Carlés, Gerardo. "El declive del kirchnerismo y las mutaciones del peronismo." Nueva Sociedad 249 (2014): 4-15.

- Annunziata, Rocío. "La figura del" hombre común" en el marco de la legitimidad de proximidad: ¿un nuevo sujeto político?" Astrolabio Nueva Época: Revista digital del Centro de Investigaciones y Estudios sobre Cultura y Sociedad 10 (2013): 127-155.

- Annunziata, Rocío. "Más allá de la promesa electoral. Repensar la representación en Argentina." Sudamérica: Revista de Ciencias Sociales 3 (2014): 137-154.

- Anuzziata, Rocío "El candidato es el proyecto": la construcción de la narrativa kirchnerista en Riorda, Mario y Rincón, Omar (eds): Comunicación gubernamental en acción: narrativas presidenciales y mitos de gobierno, Buenos Aires, Biblos, 2016

- Aronskind, Ricardo \& Vommaro, Gabriel. Campos de batalla. Las rutas, los medios y las plazas en el nuevo conflicto agrario. Buenos Aires: UNGS-Prometeo. 2010

- Barbosa, Sebastián., \& Barros, Eduardo. "Los senderos del tercer Kirchnerismo: Equilibrio económico, estabilización política y profundización social". Revista Sul-Americana de Ciência Política, 1(1), 2013, 33-52.

- Barros, Sebastián. "Populismo, pueblo y liderazgo en América Latina." Colombia Internacional 82 (2014): 297-302.;

- Burdman, Julio. "Alfas, ranas y testimoniales: la cultura política de las elecciones legislativas de medio término en Argentina”. Postdata, 15(1), 2010.

- Calvo, Ernesto. "Argentina, elecciones legislativas 2005: consolidación institucional del kirchnerismo y territorialización del voto." Revista de ciencia política (Santiago) 25.2 (2005): 153160.

- Casullo, María Esperanza. ¿¿En el nombre del pueblo? Por qué estudiar al populismo hoy." Postdata 19.2 (2014)

- Catterberg, Gabriela, and Valeria Palanza. "Argentina: dispersión de la oposición y el auge de Cristina Fernández de Kirchner " Revista de ciencia política (Santiago) 32.1 (2012): 3-30

- Cecilia Lesgart, «Argentina 2007. Notas coyunturales sobre un año electoral», L'Ordinaire des Amériques, 208-209 | 2008, 229-254.

- Cheresky, Isidoro (2003) En nombre del pueblo y de las convicciones: Posibilidades y límites del gobierno sustentado en la opinión pública. POSTData, 9, 83-123

- Cheresky, Isidoro. "Argentina. Cambio de rumbo y recomposición política: Néstor Kirchner cumple un año de gobierno." Nueva Sociedad 193 (2004): 4-16.

- Clerici, P. (2016). Juegos de Congruencia: Las Estrategias de Alianzas Electorales de la UCR y el PJ en Argentina (1983-2013). Revista Uruguaya de Ciencia Política, 25(2).

- Flax, Rocío. "La caracterización de la juventud peronista en el discurso de Cristina Fernández de Kirchner. Cadernos de Linguagem e Sociedade, 16(1), 2015, 61-80 
- Freidenberg, Flavia “¿Qué es el populismo? Enfoques de estudio y una nueva propuesta de definición como un estilo de liderazgo. el populismo en Latinoamérica: teoría, historia y valores. Francia: Presses Universitairess de Bordeaux. 2012

- García Delgado, Daniel. "De la agenda de sintonía fina a la de estabilización: la lucha por el modelo". Revista Estado y Políticas Públicas No 2. 2014. Pp.15-18

- González, Malala. "Configurar el relato: Estética y montaje de imágenes performáticas en los festejos del Bicentenario Nacional". Anales del Instituto de Arte Americano e Investigaciones Estéticas. Mario J. Buschiazzo (Vol. 45, No. 2, 2015, pp. 119-132).

- Hiller, Renata. "Matrimonio igualitario y espacio público en Argentina” en Clericó, L. y Aldao M. -comp. Matrimonio Igualitario en la Argentina. Perspectivas sociales, políticas y jurídicas, Buenos Aires: Eudeba. 2010.

- Hirschman, Albert O. Salida, vozy lealtad. Fondo de Cultura Económica. México, 1977.

- Laclau, E. (2005) La Razón populista, FCE, Buenos Aires

- Laclau, Ernesto, and Chantal Mouffe. Hegemony and socialist strategy: Towards a radical democratic politics. Verso, London, 1985.

- Laclau, Ernesto. "La democracia y el problema del poder", en Actuel Marx, ¿Pensamiento único en filosofía política?, Buenos Aires, K\&ai Ediciones. 2001 pp. 185- 196.

- Larrondo, Marina. "El Discurso Político Kirchnerista hacia la juventud en contextos de actos de militancia". Astrolabio, (11). 2013.

- Levitsky, Steven, and Kenneth M. Roberts, eds. The resurgence of the Latin American left. JHU Press, 2013.

- Martín Retamozo, «Intelectuales, kirchnerismo y política. Una aproximación a los colectivos de intelectuales

- Montero, Ana Soledad, and Lucía Vincent. "Del" peronismo impuro" al" kirchnerismo puro": la construcción de una nueva identidad política durante la presidencia de Néstor Kirchner en Argentina (2003-2007)." Postdata 18.1 (2013): 0-0.

- Montero, Ana Soledad, and Lucía Vincent. "Del" peronismo impuro" al" kirchnerismo puro": la construcción de una nueva identidad política durante la presidencia de Néstor Kirchner en Argentina (2003-2007)." Postdata 18.1 (2013):

- Montero, Ana Soledad. Puesta en escena, destinación y contradestinación en el discurso kirchnerista (Argentina, 2003-2007). Discurso \& Sociedad, 3(2), 2009. 316-347.

- Muñoz, María Antonia, and Martín Retamozo. "Hegemonía y discurso en la Argentina contemporánea: Efectos políticos de los usos de" pueblo" en la retórica de Néstor Kirchner." Perfiles latinoamericanos 16.31 (2008): 121-149.

- Natanson, José. El presidente inesperado. Editorial Homo Sapiens, Buenos Aires. 2004

- O'donnell, Guillermo. Apuntes para una teoría del Estado. Revista Mexicana de Sociología, 1978 1157-1199.

- Ollier, María Matilede. "Liderazgo presidencial y jefatura partidaria: entre la confrontación y el pacto (2003-2005)". Revista Temas \& Debates 10, (2005) pp. 7-33.

- Ostiguy, Pierre. "Exceso, representación y fronteras cruzables:" institucionalidad sucia", o la aporía del populismo en el poder." Postdata 19.2 (2014)

- Peruzzotti, Enrique. "Populismo y representación democrática." En AAVV El retorno del pueblo. Populismo y nuevas democracias en América Latina (2008): 55-73.

- Piana, Ricardo Sebastián, and Noelia S. Baeza. "Candidatos a medida ¿Cómo se construyó el candidato que le ganó a los Kirchner?" Revista de la Facultad de Derecho y Ciencias Políticas 43.119 (2013): 773-800. 
- Quilici, Federico., and Rinaldi Fernando. "La Constitución de la "Concertación Plural" en Catamarca, Río Negro y Neuquén: Desnacionalización y Fragmentación Política Documento de Trabajo No30." (2007), UNSAM.

- Retamozo, Martín, and María Belén Morris. "Sindicalismo y política. La Central de Trabajadores de la Argentina en tiempos kirchneristas." Estudios sociológicos 33.97 (2015): 63-87.

- Retamozo, Martín. "Movimientos sociales, política y hegemonía en Argentina." Polis. Revista Latinoamericana 28 (2011).

- Roberts, Kenneth M. "Neoliberalism and the transformation of populism in Latin America: the Peruvian case." World politics48.1 (1995): 82-116.

- Rocca Rivarola, María Dolores. "De Néstor y Cristina. De Perón y Evita". Reflexiones sobre lo acontecido con la militancia kirchnerista y la identidad peronista desde 2003 hasta hoy." Revista SAAP 9.1 (2015): 143-172.

- Rocca Rivarola, Dolores "De Néstor y Cristina. De Perón y Evita". Reflexiones sobre lo acontecido con la militancia kirchnerista y la identidad peronista desde 2003 hasta hoy. Revista SAAP, 9(1), 2013, 143-172.

- Rocca Rivarola, Dolores. Definiciones de pertenencia e identidades oficialistas en la Argentina de Néstor Kirchner y el Brasil de Luiz Inácio Lula da Silva. En Cheresky (Ed.) Ciudadanía y legitimidad democrática en América Latina, CLACSO-Prometeo, Buenos Aires. 2011.

- Rodríguez, Darío A. Populismo y liderazgo en la democracia argentina: Un cruce comparativo entre el menemismo y el kirchnerismo. Postdata, 19(2), 2014.

- Rodríguez, Darío. Cambios en la vida política argentina y la constitución de los liderazgos de Carlos Menem (1989-1995) y Néstor Kirchner (2003-2007). En Cheresky y Dabene (comp.) Ciudadanía y representación política, Argentina en perspectiva comparada. CLACSOPROMETE, Buenos Aires. 2012.

- Santarcángelo, Juan E., Juan Fal, and Germán Pinazo. "Los motores del crecimiento económico en la Argentina: rupturas y continuidades." Investigación económica 70.275 (2011): 93114.

- Schuttenberg, Mauricio. La reconfiguración de las identidades "nacional populares": Los puentes discursivos para la inserción de tres tradiciones políticas en el espacio "transversal kirchnerista". Sociohistórica, (28), 41-73. 2011

- Schuttenberg, Mauricio. Las identidades nacional populares: De la resistencia noventista a los años kirchernistas. Eduvim. Villa María. 2014

- Sun Tzu (2015) "El arte de la guerra" en AAVV Genios del arte de la estrategia militar (I). Ediciones LAVP. New York.

- Svampa, Maristella. . "The end of Kirchnerism." New Left Review 53.Sept.-Oct : 2008, 79-95

- Svampa, Maristella. "Argentina, una década después: Del «que se vayan todos» a la exacerbación de lo nacional-popular”. Nueva Sociedad, (235), 2011, 17-34.

- Tagina, María Luisa. Las Elecciones Legislativas 2013 en Argentina. Revista Latinoamericana de Política Comparada, 45. 2014.

- Tagina, María Luisa. Elecciones de 2009 en Argentina: cambios en la distribución del poder y nuevos desafíos de cara a las presidenciales. América Latina: política y elecciones del bicentenario (2009-2010). Madrid: Centro de Estudios Políticos y Constitucionales. 2011.

- Torre, Juan Carlos. "Los desafíos de la oposición en un Gobierno peronista”, en Torre y otros, Entre el abismo y la ilusión. Peronismo, democracia y mercado, Buenos Aires, Norma. 1999

- Tsebelis, George. Nested games: Rational choice in comparative politics. Vol. 18. Univ of California Press, 1990. 
- Varesi, Gastón. Argentina 2002-2011: neodesarrollismo y radicalización progresista. Realidad Económica, 264, 2011, 33-59.

- Vázquez, Melina. "En torno a la construcción de la juventud como causa pública durante el kirchnerismo: principios de adhesión, participación y reconocimiento." Revista Argentina de Estudios de Juventud [En línea], 1.7 (2013)

- Weyland, Kurt. "The threat from the populist left." Journal of Democracy 24.3 (2013): 18-32.

- Zermeño, Sergio. "El regreso del líder: crisis, neoliberalismo y desorden." Revista Mexicana de Sociología (1989): 115-150. 